\title{
THE LAW AND POLICY OF OPIOIDS FOR PAIN MANAGEMENT, ADDICTION TREATMENT, AND OVERDOSE REVERSAL
}

\author{
Corey S. Davis* \& Derek H. Carr** \\ TABLE OF CONTENTS
}

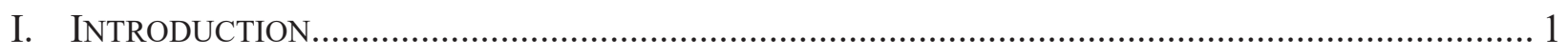

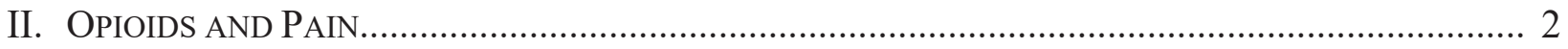
A. The burden of untreated pain.
B. The importance of opioid therapy
C. Potential pitfalls of opioid therapy

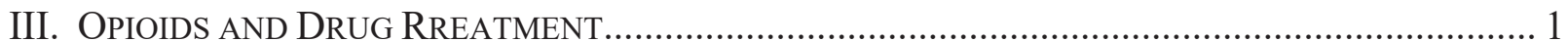
A. The burden of untreated opioid addiction
B. Medication assisted treatment
C. Federal Regulation of MAT: Historical Context
D. Federal Regulation of Methadone
E. Federal Regulation of Buprenorphine
F. Insurance Coverage of MAT

IV. ACCESS TO NALOXONE. 26

A. Access to emergency overdose treatment

B. Addressing legal and policy barriers to naloxone access

1. Immunity

2. Prescribing outside of the traditional prescriber relationship

3. Overdose Good Samaritan laws

4. Over-the-counter access

V. CONCLUSION

\section{INTRODUCTION}

Perhaps few drugs are more emblematic of the human condition than those derived from opioids. Preparations of the opioid poppy have been used for thousands of years for both their euphoric and analgesic effects. These natural preparations have been joined by synthetic and semi-

* Corey S. Davis Deputy Director, Network for Public Health Law, Southeastern Region

** Derek H. Carr Legal Fellow, Network for Public Health Law, Southeastern Region 
synthetic products that can be hundreds and sometimes thousands of times stronger, but the main reasons for their popularity-relief of physiological and psychological pain-remain unchanged. In the United States, pain is so prevalent and opioid medications so widely available that overdoses of prescription opioids and heroin have become a public health crisis, responsible for tens of thousands of deaths per year. At the same time, and despite the efforts of dedicated reformers, millions of people in developing countries suffer agonizing pain that could be relieved with a few dollars' worth of morphine.

In an ironic twist, opioids have proven extremely effective in reducing many of the harms associated with opioid misuse, but lack of evidence-based law and policy conspire with stigma to make it difficult for many people to access these life-saving treatments. The chief medications used for the treatment of addiction, methadone and buprenorphine, are considered "Essential Medications" by the World Health Organization ("WHO"), but are often not available even in the extremely well-resourced United States. The same is often true regarding the medication naloxone, itself derived from the opioid thebaine, which quickly and effectively reverses opioid overdose but is often not readily available when and where it is needed.

In this paper, we address these issues in turn, and conclude with a brief discussion of promising legal and policy approaches to reduce the terrible burdens of untreated pain, opioid addiction, and overdose morbidity and mortality. We begin, in Part II, by discussing the importance of opioids in the treatment of some types of pain, as well as inequities in access to opioids - and set the stage for the rest of the paper, which focuses on attempts to address the problems caused by a misapplication of opioid therapy to conditions for which it is not indicated. In Part III, we highlight the importance of opioids for the treatment of opioid use disorder, and the social, legal, and policy barriers to access of this evidence-based treatment. In Part IV, we note innovations in access to the medication naloxone, including unprecedented actions at the state level to break through barriers caused by the drug's status as a prescription medication under federal law. We conclude in Part V with some brief thoughts regarding promising approaches to reduce the twin public health crises of untreated pain and the negative effects of opioid abuse, addiction, and overdose.

\section{OPIOIDS AND PAIN}

\section{A. The Burden of Untreated Pain}

Untreated or inadequately treated pain is a serious medical, societal, and economic concern. "Pain affects millions of Americans; contributes greatly to national rates of morbidity, mortality, and disability; and is rising in prevalence."1 Chronic pain is extremely common in the United States and throughout the world, ${ }^{2}$ with an estimated 116 million Americans suffering from pain

${ }^{1}$ Inst. of Med. (US) COMm. ON AdVAnCing PAin Research, CARE, AND EduC., Relieving PAIN IN AMERICA: A BLUEPRINT FOR TRANSFORMING PREVENTION, CARE, EDUCATION, AND RESEARCH 5 (2011) (hereinafter "IOM Report").

2 Peter F.M. Verhaak et al., Prevalence of Chronic Benign Pain Disorder Among Adults: A Review of the Literature, 77 PAIN 231, 231-34 (1998); Adley Tsang et al., Common Chronic Pain Conditions in Developed and Developing Countries: Gender and Age Differences and Comorbidity with Depression-Anxiety Disorders, 9 J. PAIN 883, 886 (2008) (Reporting that the age-standardized prevalence of chronic pain in the previous 12 months was $37.3 \%$ in developed countries and $41.1 \%$ in developing countries). 
that persists for months or longer. ${ }^{3}$ It "affects more Americans than diabetes, heart disease and cancer combined." 4 In a recent systematic survey, more than one-quarter of Americans reported that they had low back pain that lasted at least one day in the past three months; the numbers were $15 \%$ for migraine or severe headache and almost $14 \%$ for neck pain. ${ }^{5}$ In a separate report, knee pain was reported by nearly $20 \%$ of Americans, and shoulder pain by $9 \%{ }^{6}$ Rates of chronic pain appear to be rising, a trend that is expected to continue for a variety of reasons, including the aging of the American population. ${ }^{7}$ Acute pain, which can and often does become chronic, is also highly prevalent among Americans. ${ }^{8}$

In addition to the morbidity caused by pain itself, chronic pain is associated with a number of other negative conditions including anger, depression, and anxiety. ${ }^{9}$ While the economic cost of pain is difficult to measure, it is clear that both direct costs in the form of medical expenditures as well as indirect costs in the form of lost productivity and lower quality of life are high and rising. One recent review estimated the cost of persistent pain in the United States at approximately \$560 to $\$ 635$ billion annually. ${ }^{10}$ The indirect and direct cost of lower back pain alone has been estimated at a minimum of between approximately \$20 and \$120 billion per year in the United States, with one estimate of over $\$ 624$ billion per year. ${ }^{11}$ One study found biennial expenditures on outpatient care for chronic back to have increased from $\$ 26.9$ billion in 2000-01 to $\$ 52.8$ billion in 2006-7. ${ }^{12}$

${ }^{3}$ IOM Report, supra note 1 , at 19.

${ }^{4}$ American Acad. of Pain Med., AAPM Facts and Figures on Pain, http://www.painmed.org [https://perma.cc/MYF2-LF5Y] (last visited Nov. 1, 2016).

${ }^{5}$ Richard A. Deyo et al., Back Pain Prevalence and Visit Rates: Estimates from U.S. National Surveys, 2002, 31 SPINE 2724, 2725 (2006).

${ }^{6}$ IOM Report, supra note 1 , at 62.

${ }^{7}$ IOM Report, supra note 1, at 62-64 ("[C]hronic pain rates are likely to continue to rise, for at least five reasons."); J. Chiu et al., Access to Therapeutic Opioids: A Plan of Action for Donors, NGOs, and Governments, 24 TEMPLE INT'L \& COMP. L. J. 417, 420 (2011) (noting that rates of cancer and HIV cases are likely to increase, particularly in the developing world).

${ }^{8}$ H. Kehlet et al., Persistent Postsurgical Pain: Risk Factors and Prevention, 367 LANCET 1618,1619 (2006) (estimating that 20-30\% of breast surgery patients, 30-50\% of coronary bypass patients (5-10\% debilitating), and 10\% of caesarean patients suffer post-surgery chronic pain (4\% debilitating)).

9 Lachlan A. McWilliams et al., Depression and Anxiety Associated with Three Pain Conditions: Results from a Nationally Representative Sample, 111 PAIN 77, 79 (2004) (finding that psychiatric disorders were much more pronounced in individuals with arthritis, migraine, and back pain than in individuals without those conditions); C. R. Green, et al., Cancer-Related Chronic Pain: Examining Quality of Life in Diverse Cancer Survivors, 117 CANCER 1994, 1999 (2011) (pain associated with depression).

${ }^{10}$ Darrell J. Gaskin \& Patrcik Richard, The economic costs of pain in the United States, $13 \mathrm{~J}$. PAIN 715, 715, 723 (2012) (calculating the cost of pain-related health care at \$261-300 billion and lost productivity at $\$ 297-336$ billion).

${ }^{11}$ Simon Dagenais et al., A Systematic Review of Low Back Pain Cost of Illness Studies in the United States and Internationally, 8 SPINE J. 8, 19 (2008).

12 Monica Smith et al., Aging Baby Boomers and the Rising Cost of Chronic Back Pain: Ssecular Trend Analysis of Longitudinal Medical Expenditures Panel Survey Data for Years 2000 
In light of the human suffering and economic burdens associated with pain, treating and preventing it is both a key challenge and a moral imperative. ${ }^{13}$ The Institute of Medicine devoted a nearly 400 page report to untreated pain in 2011, declaring it "a significant public health problem" for which a "population health-level strategy is needed." 14 The WHO Expert Committee on Cancer Pain Relief has declared that "[f]reedom from pain should be seen as a right ... and access to pain therapy as a measure of respect for this right." 15

\section{B. The Importance of Opioid Therapy}

Opioids have been known to humans for at least 5,000 years, with their use for treatment of pain recorded as early as approximately 1,550 B.C. ${ }^{16}$ Opioids activate a number of receptors, most notably the mu receptor. ${ }^{17}$ These receptors affect a number of mental and physical states, including euphoria, sedation, supraspinal analgesia, and respiratory depression. ${ }^{18}$ They are primarily located in the brain, but are also found in the heart, immune system, and gastrointestinal tract, among other places. ${ }^{19}$

Opioids can be broadly categorized into two classifications: agonists, which stimulate the opioid receptors, and antagonists, which bind to the opioid receptor but do not stimulate them. ${ }^{20}$

to 2007, 36 J. MANiPUlative AND PhysiologiCAl Theraputics. 2, 7 (2013). (The same study found a 30\% increase in the prevalence of back pain during the study period.) Id. At 6 . These costs are almost certainly higher today.

13 Jane C. Ballantyne \& Jianren Mao, Opioid Therapy for Chronic Pain, 349 NEw EnG. J. MeD. 1943 (2003) ("[O]pioid therapy can relieve pain and improve mood and functioning in many patients with chronic pain."); Jeffrey L. Apfelbaum et al., Postoperative Pain Experience: Results from a National Survey Suggest Postoperative Pain Continues to be Undermanaged, 97 ANESTHESIA \& ANALESIA 534 (2003) ("Prevention and effective relief of acute pain may improve clinical outcomes, avoid clinical complications, save health care resources and improve quality of life.").

${ }^{14}$ IOM Report, supra note 1, at 5-7.

15 World Health Org., Cancer Pain Relief and Palliative Care 10-11 (1990), http://whqlibdoc.who.int [https://perma.cc/K87W-AZQP].

16 See Anil Aggrawal, Narcotic Drugs (2001) (documenting references to opioids in Sumerian, Assyrian, and Egyptian texts prior to 1,500 B.C.); Andrea M. Trescot et al., Opioid Pharmacology, 11 PAIN PHYSICIAN S133, S133 (2008) ("Ancient Egyptian papyrus records reported the use of opium for pain relief.").

17 Trescot et al., supra note 16, at S134; Hasan Pathan \& John Williams, Basic Opioid Pharmacology: An Update, 6 BRITISH J. PAIN 11, 11-12, 14 (2012) ("All opioids used in clinical practice today exert their action, at least in part, at the MOP receptor." The mu receptor was named for the first letter of the first compound shown to bind to it: morphine.).

18 Trescot et. al., supra note 16 , at S134.

${ }^{19}$ Pathan \& Williams, supra note 17, at 12.

${ }^{20}$ Some opioids have elements of both categories, and are classified as partial agonists or agonist/antagonists. Trescot et al., supra note 16, at S138-39; Pathan \& Williams, supra note 17, at 11-12. 
Morphine, the prototypical opioid agonist, was isolated in $1804 .{ }^{21}$ Since that time, a large number of semi-synthetic and fully synthetic opioids have been created and produced. ${ }^{22}$ In the United States and most other high-resource countries, therapy with these medications has become the mainstay of treatment of acute post-operative pain, and may be indicated for some patients who suffer surgery-related chronic pain ${ }^{23}$ and severe cancer pain. ${ }^{24}$ They are also important for the treatment of pain in individuals with HIV or AIDS for whom pain is not well controlled with other medications. ${ }^{25}$ As will be described in the next Section, some opioids are also extremely effective in the treatment of opioid addiction. In recognition of the vital nature of access to opioids, the World Health Organization lists three opioids-codeine, morphine, and methadone-as "essential medicines" that "should be available at all times in adequate amounts and in the appropriate dosage forms." 26

Unfortunately, this is not always the case ${ }^{27}$ In a large number of countries, patients with severe HIV, cancer, and post-operative pain have little or no access to opioid treatment. ${ }^{28}$ Despite having

${ }^{21}$ Trescot et al., supra note 16, at 141; Pathan \& Williams, supra note 17, at 11 (Pathan and Williams place the date of isolation of morphine at 1806.).

22 All of the currently prescribed opioid analgesics, such as oxycodone, hydrocodone, and fentanyl, are synthetic or semi-synthetic compounds that mimic the general action of the opium poppy but are not necessarily derived from it. Pathan \& Williams, supra note 17, at 11.

${ }^{23}$ Veerabhadram Garimella \& Christina Cellini, Postoperative Pain Control, 26 CLINICS Colon Rectal Surgery 191, 192 (2013); Rosemary C. Polomano, et al., Perspective on Pain Management in the 21st Century, 9 PAIn MGMT. Nursing 2008 S3, S6 (2008) ("Opioids used in clinical practice remain the cornerstone of moderate and severe acute pain treatment").

24 Augusto Caraceni, et al., Use of Opioid Analgesics in the Treatment of Cancer Pain: Evidence-Based Recommendations from the EAPC, 13 THE LANCET ONCOLOGY e58 (describing opioid analgesics as "crucial to the relief of cancer pain."); M.H.J. van den Beuken-van Everdingen et al., Prevalence of Pain in Patients with Cancer: A Systematic Review of the Past 40 Years, 18 ANNALS ONCOLOGY 1437, 1441 (2007) (finding that more than 50\% of cancer patients report pain, with more than one-third of these patients rating their pain as moderate or severe).

${ }^{25}$ G. Newshan \& JA. Staats, Evidence-Based Pain Guidelines in HIV Care, 24 J. Assoc. Nurses AIDS CARE S112, S115 (2013); William Breitbart, A CliniCAL Guide to Supportive \& PAlliative CARE FOR HIV/AIDS 85, 104-06 (Joseph F. O’Neill et al. eds., 2003) (describing opioid medications as a "mainstay" in the treatment of moderate-to-severe pain in patients with cancer and HIV).

${ }^{26}$ World Health ORG., WHO Model List of Essential Medicines 1, 40 (2015) (listing codeine, morphine, and methadone as essential medicines); World HEALTH ORG., ThE UsE OF ESSENTIAL DRUGS: EIGHTH REPORT OF THE WHO EXPERT COMMITTEE 2 (1998).

27 See InT'L NARCotics CONTROL BD., NARCotic Drugs: Estimated WorLd REQUiREMENTS FOR 2015, 222-29 (2014) (showing wide disparities in consumption of drugs between member states).

${ }^{28}$ See generally E. Anderson \& CS. Davis, Breaking the Cycle of Preventable Suffering: Fulfilling the Principle of Balance, 24 TEMP. INT'L \& COMP. L.J. 329, 330 (2010) (noting that “few burdens are as fundamentally crippling and so elegantly reflect global health disparities as untreated pain.”); D. Lohman, et al., Access to Pain Treatment as a Human Right, 8 BMC MED. 1, 6 (2010) (noting that lack of pain treatment medicine in some countries is "both perplexing and 
less than $5 \%$ of the world's population, the United States consumes more than $80 \%$ of the world's opioids. ${ }^{29}$ In 2013, the average per-capita consumption of the opioid oxycodone in the United States was just under $200 \mathrm{mg}$, while the vast majority of countries reported less than $10 \mathrm{mg}$ and 7 reported less than $1 \mathrm{mg} .{ }^{30}$ The top 6 morphine consuming countries (Austria, Canada, Denmark, USA, New Zealand and Switzerland) consumed more of the drug than the bottom 134 combined. The average consumption of these six countries was approximately $94 \mathrm{mg}$ per person. ${ }^{31}$ Conversely, eighty-six countries reported consuming less than $2 \mathrm{mg}$ per capita, while sixty-seven reported less than $1 \mathrm{mg}$ per capita. ${ }^{32}$ Because of this disparity in access to clinically indicated opioids, it has been estimated that 4.8 million people with moderate to severe cancer pain go untreated every year, most in the developing world. ${ }^{33}$

While less pronounced, these disparities exist in the United States as well. Numerous studies have documented higher rates of pain among women compared to men, and systematic undertreatment of pain appears to be prevalent among at least some racial and ethnic minorities. ${ }^{34} \mathrm{~A}$ recent meta-analysis found that Hispanic and Latino Americans were 22\% less likely to be prescribed opioid analgesics than their Caucasian counterparts, while African Americans were $29 \%$ less likely than similarly situated Caucasian to be prescribed opioids. ${ }^{35}$

\section{Potential Pitfalls of Opioid Therapy}

At the population level, however, the problem in the United States is more often overprescription. While patients with severe cancer pain in many countries find it impossible to access any opioids at all, in America enough opioids were prescribed in 2010 to medicate every adult

inexcusable"); Frank Brennan et al., Pain Management: A Fundamental Human Right, 105 ANESTHESIA \& ANALGESIA 205 (2007) (describing "a major gap between and increasingly sophisticated understanding of the pathopsychology of pain and widespread inadequacy of its treatment.").

${ }^{29}$ D. R. Solanki, et al., Monitoring Opioid Adherence in Chronic Pain Patients: Assessment of Risk of Substance Misuse, 14 PAIN PHYSICIAN 119, 120 (2011).

30 Pain and Policy Studies Group, 2014 Global Consumption of Oxycodone (mg/capita), http://www.painpolicy.wisc.edu/ [https://perma.cc/GX7G-RYWP] (last visited Nov. 1, 2016) (Only seventy-six countries reported oxycodone use in 2013).

${ }^{31} I d$.

${ }^{32} \mathrm{Id}$.

${ }^{33}$ Willem Scholten, et al., The World Health Organization Paves the Way for Action to Free People From the Shackles of Pain, 105 AnESTHESIA \& ANALGESIA 1, 2 (2007).

${ }^{34}$ R. Bernabei, et al., Management of Pain in Elderly Patients with Cancer. SAGE Study Group. Systematic Assessment of Geriatric Drug Use via Epidemiology, 279 [J]AMA 1877 (1998) (black nursing home residents 63\% less likely than similarly situated whites to receive opioids for cancer pain); Inst. of Med., Unequal Treatment: Confronting RaCial and EthniC DisParities in HeAlth CARE (B. D. Smedley, et al. eds. 2003) (citing numerous examples).

35 The paper reported that these differences are "sufficently large to impact clinical outcome." S. H. Meghani, et al., Time to Take Stock: A Meta-Analysis and Systematic Review of Analgesic Treatment Disparities for Pain in the United States, 13 PAIn MEDICINE 150, 156-159 (2012). 
around-the-clock for a month. ${ }^{36}$ Nearly 20 percent of office-based physician visits where noncancer pain was either a primary symptom or diagnosis result in a prescription for opioid painkillers $^{37}$, and $31 \%$ of all emergency department visits-even those that were not pain-relatedresult in at least one opioid being prescribed. ${ }^{38}$

Unfortunately, many of these prescriptions will likely do little to help the patient, and some will cause irreversible harm. While opioids are often prescribed for acute post-surgical pain, evidence of their efficacy in treating this and other short-term pain is weak and of generally lowquality, particularly compared with other therapies. For example, a 2013 Cochrane review of the short-term use of opioids for low back pain concluded that "the current literature does not support that opioids are more effective than other groups of analgesics." 39 Similar findings have been reported for rheumatoid arthritis ${ }^{40}$ and osteoarthritis of the knee and hip. ${ }^{41}$ Even for post-surgical pain, the Cochrane reviews found that the most effective therapy was not an opioid or opioid in combination with another medication, but rather a combination of ibuprofen and acetaminophen. ${ }^{42}$ A systematic review of pain relief following third molar extractions similarly found that a combination of acetaminophen and ibuprofen "appeared to provide analgesia at least equivalent to those of commonly prescribed opioid combination formulations." 43

${ }^{36}$ Centers for Disease Control and Prevention, Vital Signs: Overdoses of Prescription Opioid Pain Relievers-United States, 1999-2008, 64 Morbidity AND MorTAliLty WKLy. ReP. 1487492 (Nov. 1, 2011).

${ }^{37}$ M. Daubresse, et al., Ambulatory Diagnosis and Treatment of Nonmalignant Pain in the United States, 2000-2010, 51 MED. CARE 870, 875 (2013).

${ }^{38}$ M. Mazer-Amirshahi, et al., Rising Opioid Prescribing in Adult U.S. Emergency Department Visits: 2001-2010, 21 ACAD. EMERG. MED. 236, 238 (2014).

${ }^{39}$ L. E. Chaparro, et al., Opioids Compared to Placebo or Other Treatments for Chronic LowBack Pain, The Cochrane DATABASE Sys. ReV. (Aug. 27, 2013), http://onlinelibrary.wiley.com [https://perma.cc/P2QG-7A6C]; Opioids were found to be not effective at all at treating pain related to sciatica. R. A. Lewis, et al., Comparative Clinical Effectiveness of Management Strategies for Sciatica: Systematic Review and Network Meta-Analyses, 15 SPINE J. 1461 (2015).

40 S. L. Whittle, et al., Opioid Therapy for Treating Rheumatoid Arthritis Pain, CochranE $\begin{array}{llll}\text { DATABASE SYS. } & \text { REV. } & \text { (Nov. } & \text { 9, }\end{array}$ http://onlinelibrary.wiley.com/doi/10.1002/14651858.CD003113.pub3/abstract [https://perma.cc/KE4X-NT7W].

${ }^{41}$ B. R. da Costa, et al., Oral or Transdermal Opioids for Osteoarthritis of the Knee or Hip, COChrane DATABASE Sys. REV. (Sept. 17, 2014), http://onlinelibrary.wiley.com [https://perma.cc/YD9Q-CUCU] (finding that "the small mean benefit of non-tramadol opioids are contrasted by significant increases in the risk of adverse events" and that the effects of opioids on pain "were of questionable clinical relevance.").

42 Donald Teater, NAT'L SAFETy COUNCIL, EVIDENCE FOR THE EFFICACY OF PAIN MEDiCATIONS, http://www.nsc.org [https://perma.cc/837Z-MMEM] (last visited Nov. 1, 2016) (reviewing Cochrane reports).

43 P. A. Moore \& E. V. Hersh, Combining Ibuprofen and Acetaminophen for Acute Pain Management After Third-Molar Extractions: Translating Clinical Research to Dental Practice, 144 J. Am. Dental Assoc. 898 (2013). 
Although opioids are often prescribed for chronic non-cancer pain, there is surprisingly little evidence supporting this practice. ${ }^{44}$ A 2010 Cochrane review of the use of chronic opioids for chronic non-cancer pain found that many people discontinue opioid therapy due to negative side effects or lack of adequate pain relief, and there is only "weak evidence" that those who continue with opioids experience "clinically significant pain relief." 45 A 2015 systematic review found no studies evaluating opioid vs. non-opioid therapy over periods of more than one year; the studies that do exist suggested that chronic opioid therapy "is associated with increased risk of overdose, opioid abuse and dependence, fractures, myocardial infarction, and use of medications to treat sexual dysfunction."46 The American Academy of Neurology recently concluded that "[t]he risks for chronic opioid therapy for some chronic conditions such as headache, fibromyalgia, and chronic low back pain likely outweigh the benefits." 47

Even when used as directed for conditions for which they are indicated, opioids often cause negative side effects including constipation, nausea, vomiting, and hormonal changes. ${ }^{48}$ Perversely, it appears that, for some number of people, receiving opioids actually causes an increase in pain sensitivity. ${ }^{49}$ When opioids are discontinued after more than five to seven days, most patients will suffer withdrawal symptoms, which can range from mild discomfort to painful muscle pains, diarrhea, and nausea. Perhaps most alarmingly, some number of people who receive chronic opioids-between $8 \%$ and $12 \%$, according to a recent systematic review of the literature-

${ }^{44}$ I. Kissin, Long-Term Opioid Treatment of Chronic Nonmalignant Pain: Unproven Efficacy and Neglected Safety?, 6 J. PAIN RES. 513 (2013) (concluding that there is "no strong evidencebased foundation for the conclusion that long-term opioid treatment of chronic nonmalignant pain is effective."); C. R. Chapman, et al., Opioid Pharmacotherapy for Chronic Non-Cancer Pain in the United States: A Research Guideline for Developing an Evidence-Base, 11 THE J. OF PAIN: OFFICIAL J. OF THE AM. PAIN SOC'Y 807 (2010) (discussing lack of effectiveness of long-term use of opioids for chronic non-cancer pain).

${ }^{45}$ M. Noble, et al., Long-Term Opioid Management for Chronic Noncancer Pain, THE COCHRANE DATABASE OF SYS. REV. (Jan. 20, 2010), http://onlinelibrary.wiley.com [https://perma.cc/34FD-BNMT].

${ }^{46}$ R. Chou, et al., The Effectiveness and Risks of Long-Term Opioid Therapy for Chronic Pain: A Systematic Review for a National Institutes of Health Pathways to Prevention Workshop, 162 ANNALS OF INTERN. MED. 276, 277-280 (2015) (internal citations omitted).

${ }^{47}$ G. M. Franklin, Opioids for Chronic Noncancer Pain: A Position Paper of the American Academy Of Neurology, 83 NeURology 1277, 1283 (2014).

${ }^{48}$ Pathan \& Williams, supra note 17 (citing constipation, nausea, and vomiting as side effects of opioid therapy); R. Benyamin, et al., Opioid Complications and Side Effects, 11 PAIN PHYSICIAN S105, 106-109 (2008).

49 M. Lee, ET AL., A Comprehensive Review of Opioid-Induced Hyperalgesia, 14 PAIN PHYSICIAN 145 (2011) (reviewing literature). 
will develop addiction, ${ }^{50}$ with enormous costs in terms of lost productivity, increased medical care, as well as emotional losses. ${ }^{51}$

In fact, it now seems clear that over-prescription of opioids has resulted in hundreds of thousands of preventable deaths in the United States, ${ }^{52}$ which is in the grips of an overdose epidemic that has been building for nearly two decades. ${ }^{53}$ Increased prescribing of opioids is a key factor in the rise in preventable deaths. ${ }^{54}$ Opioid prescriptions nearly quadrupled from 1999 to 2010, accompanied by a nearly identical rise in the rate of prescription opioid-related deaths. ${ }^{55}$ In 2014, nearly 19,000 Americans died of prescription opioid overdoses, a rate of more than 50 per day. ${ }^{56}$ While the exact relationship is debated, it is clear that this increase in opioid prescriptions and related addiction has also helped fuel the recent increase in heroin overdose in the United States, which more than tripled between 2010 and 2013. ${ }^{57}$ Despite the now well-known risks of opioid therapy and the growing acknowledgement that its use is not effective for many of the conditions that it is prescribed to treat (or, at best, that it is no more effective than other therapies, despite carrying higher risks), long-term use of opioids has been increasing, and millions of Americans are on chronic opioid treatment for non-cancer pain. ${ }^{58}$ There are a number of reasons for this disconnect, including well-intentioned efforts to address untreated pain. ${ }^{59}$ However, the United States also suffered an onslaught of marketing from makers of opioid medications that

${ }^{50}$ K. E. Vowles, et al., Rates of Opioid Misuse, Abuse, and Addiction in Chronic Pain: A Systematic Review and Data Synthesis, 156 PAIN 569, 573 (2015).

${ }^{51}$ H. G. Birnbaum, et al., Societal Costs of Prescription Opioid Abuse, Dependence, and Misuse in the United States, 12 PAIN MED. 657, 661-62 (2011) (estimating costs due to prescription opioid abuse at approximately $\$ 55$ billion in 2007).

52 R. A. Rudd, et al., Increases in Drug and Opioid Overdose Deaths - United States, 20002014, 64 MorbIDITY AND MORTALITY WKLY REP. 1378, 1380 (2015) (reporting that "From 2000 to 2014 nearly half a million persons in the United States have died from drug overdoses . . . Opioids, primarily prescription pain relievers and heroin, are the main drugs associated with overdose deaths.").

${ }^{53} \mathrm{Id}$.

54 A. S. Bohnert, et al., Association Between Opioid Prescribing Patterns and Opioid Overdose-Related Deaths, 305 [J]AMA 1315, 1321 (2011); F. Modarai, et al., Relationship of Opioid Prescription Sales and Overdoses, North Carolina, 132 Drug AlCOHOL DePENDENCE 81 (2013).

${ }^{55}$ Centers for Disease Control and Prevention, supra note 36.

${ }^{56}$ Centers for Disease Control and Prevention, Number and Age-Adjusted Rates of DrugPoisoning Deaths Involving Opioid Analgesics and Heroin: United States, 2000-2014, http://www.cdc.gov [https://perma.cc/EZK4-V64K] (last visitied Nov. 1, 2016).

${ }^{57}$ R. A. Rudd, et al., supra note 52; W. M. Compton, et al., Relationship Between Nonmedical Prescription-Opioid Use and Heroin Use, 374 N ENG. J. MED. 154 (2016) (discussing transition to heroin use).

${ }^{58}$ D. Boudreau, et al., Trends in Long-term Opioid Therapy for Chronic Non-Cancer Pain, 18 PhARMACOEPIDEMIOL DRUG SAF. 1166 (2009).

${ }^{59}$ See, e.g., D. E. Joranson, et al., Pain Management, Controlled Substances, and State Medical Board Policy: A Decade of Change, 23 J PAIn SyMPTOM MANAGE 138 (2002). 
targeted doctors with sometimes misleading information regarding the effectiveness and dangers of opioid medications. ${ }^{60}$

In some instances, this marketing crossed the line into illegality. In 2006, three Purdue executives and the corporate entity pled guilty to several federal charges related to illegal marketing of Oxycontin. ${ }^{61}$ The company continues to face criminal scrutiny; in 2015 it reached a \$24 million settlement with the Kentucky Attorney General regarding claims that it illegally marketed OxyContin as non-addictive, and a separate settlement with the New York Attorney General to resolve claims that it had illegally marketed OxyContin in the state. ${ }^{62}$ Similar claims have been made against numerous other opioid manufacturers. Insys, which makes the potent fentanyl spray Subsys, recently reached a \$1.1 million settlement with the Oregon Attorney General to resolve claims that the company improperly marketed the medication in the state and is currently under investigation by at least three other states as well as the federal government. ${ }^{63}$

In 2016, the New York Attorney General fined Endo Pharmaceuticals \$200,000 after finding that the company improperly marketed Opana ER, a powerful opioid, and instructed its sales representatives to "diminish and distort" risks associated with the medication. ${ }^{64}$ Numerous municipalities have active suits against a variety of opioid manufacturers alleging a number of claims related to illegal marketing and related claims. ${ }^{65}$ Doctors may be particularly susceptible to

${ }^{60}$ A. Kolodny, et al., The Prescription Opioid and Heroin Crisis: A Public Health Approach to an Epidemic of Addiction, 36 AnN. Rev. Pub. Health 25.1, 25.4 (2015) (documenting numerous efforts by Purdue Pharma, makers of Oxycontin, to encourage prescribing of opioids for pain); see A. Van Zee, The Promotion and Marketing of Oxycontin: Commercial Triumph, Public Health Tragedy, 99 AM. J. PuB. Health 221 (2009) (describing the aggressive promotion of Oxycontin for the "non-malignant" pain market and ensuing inrease in prescribing).

${ }^{61}$ While none served jail time, over $\$ 635$ million in fines were levied. Barry Meier, In Guilty Plea, OxyContin Maker to Pay \$600 Million, N.Y. Times, May 10. 2007.

${ }^{62}$ Press Release, New York State Office of the Attorney General, A.G. Schneiderman Announces Settlement With Purdue Pharma that Ensures Responsible and Transparent Marketing Of Prescription Opioid Drugs By The Manufacturer (Aug. 20, 2015); Press Release, Kentucky Office of the Attorney General, AG Conway Announces Two Pharmaceutical Settlements Totaling \$39.5 Million (Dec. 23, 2015).

${ }^{63}$ Or. Dep't of Justice, AG Rosenblum Settles with Pharmaceutical Company Insys over Unlawful Promotion of the Powerful Opioid Subsys (Aug. 5, 2015), http://www.doj.state.or.us/ [https://perma.cc/9UBN-LWGL]; Form 10-Q Insys Therapeutics, Inc., STREET INSIDER (Aug. 6, 2015, 6:15 PM), http://www.streetinsider.com [https://perma.cc/5SJTWDCH].

${ }^{64}$ Press Release, Attorney General Eric T. Schneiderman, A.G. Schneiderman Announces Settlement With Endo Health Solutions Inc. \& Endo Pharmaceuticals Inc. Over Marketing Of Prescription Opioid Drugs (Mar. 3, 2016) (on file with New York City Press Office).

${ }^{65}$ Lisa Girion, Judge Halts Counties' Lawsuit Against 5 Narcotic Drug Manufacturers, L. A. TIMES, Aug. 27. 2015, http://www.latimes.com/ [https://perma.cc/GV4G-QXZA]. Doctors may be particularly susceptible to such marketing because they receive little information regarding evidence-based opioid prescribing during medical school and residency training; see C. S. Davis \& D. Carr, Physician Continuing Education to Reduce Opioid Misuse, Abuse, and Overdose: Many Opportunities, Few Requirements, 163 Drug Alcohol DePEND 100 (2016). 
such marketing because they receive little information regarding evidence-based opioid prescribing during medical school and residency training. ${ }^{66}$

\section{OPIOIDS AND DRUG TREATMENT}

\section{A. The Burden of Untreated Opioid Addiction}

In 2014, nearly 2.5 million Americans had a substance use disorder involving opioids; 1.9 million of these cases involved opioid pain relievers ("OPRs") and 586,000 involved heroin. ${ }^{67}$ The prevalence of opioid addiction and opioid use disorder ("OUD") comes at great costs. Prescription opioid abuse accounted for more than $\$ 55$ billion in societal and economic costs in 2007 , including lost productivity and criminal justice costs. ${ }^{68}$ Numerous studies demonstrate that individuals with OUD have significantly higher health care costs. ${ }^{69}$ Moreover, the federal Office of National Drug Control Policy ("ONDCP”) spends more than \$25 billion annually on drug control, less than half of which is allocated for prevention and treatment. ${ }^{70}$ States and local governments spend an additional \$25 billion annually. ${ }^{71}$ Opioid addiction and OUD also comes at great personal cost.

In the last decade, Hepatitis $\mathrm{C}$ infection rates have risen dramatically due in large part to increasing prescription opioid and heroin injection and the lack of syringe exchange and sterile

${ }^{66}$ C. S. Davis \& D. Carr, Physician Continuing Education to Reduce Opioid Misuse, Abuse, and Overdose: Many Opportunities, Few Requirements, 163 DRUG Alcohol DePEND 100 (2016).

${ }^{67}$ U.S. DEP'T OF HEALTH AND HUMAN SERVICES, BEHAVIORAL HEALTH TRENDS IN THE UNITED States: Results fROM the 2014 NAtional SuRVEy On DRUG Use AND HeAlth 26-27 (2015), http://www.samhsa.gov [https://perma.cc/XM98-ZLL4].

${ }^{68}$ Howard G. Birnbaum et al., Societal Costs of Prescription Opioid Abuse, Dependence, and Misuse in the United States, 12 PAIN MED. 657, 661 (2011). This includes $\$ 25.6$ billion in lost work place productivity, $\$ 25$ billion in health care costs, and $\$ 5.1$ billion in criminal justice costs. Id.

${ }^{69}$ See, e.g., Alan G. White et al., Economic Impact of Opioid Abuse, Dependence, and Misuse, 3 AM. J. OF PHARMACY BENEFITS e59, e64 (2011) ("Mean excess annual costs per privately insured patient were $\$ 20,546$, and mean excess costs per privately insured caregiver were $\$ 1010$. Mean excess costs per Florida Medicaid patient were \$15,183."); J. Bradford Rice et al., The Economic Burden of Diagnosed Opioid Abuse Among Commercially Insured Individuals, 126 POSTGRAD. MED. 53, 55-57 (2014) (total health care costs more than twice as high for opioid abusers). Individuals with undiagnosed OUD have lower health care costs than individuals diagnosed with OUD, but their costs still exceed individuals without OUD. See Noam Y. Kirson et al., The Burden of Undiagnosed Opioid Abuse Among Commercially Insured Individuals, 16 PAIN MED. 1325, 1328 (2015).

70 Exec. Office of the President of the United States, National Drug Control Strategy: Fy 2016 Budget And Performance Summary 1, 21 tbl.1 (2015), https://www.whitehouse.gov [https://perma.cc/B2RS-5NK7].

71 JefFrey A. Miron \& Katherine WALdock, The Budgetary IMPACT OF Ending Drug ProHiBITION 5 (2010), http://object.cato.org/ [https://perma.cc/7JPE-T4QA]. 
syringe access. ${ }^{72}$ In 2015, officials linked a large HIV outbreak in Indiana to the sharing of needles used to inject prescription opioids, particularly the medication Opana. ${ }^{73}$ Moreover, as discussed elsewhere, opioid overdose now results in tens of thousands of deaths per year. ${ }^{74}$

Evidence-based treatment, particularly treatment with opioid agonists, has been shown to significantly reduce both the harmful effects and costs of OUD. However, a 2013 report from the federal Substance Abuse and Mental Health Services Administration ("SAMHSA") found that less than $20 \%$ of all individuals with opioid use disorder ("OUD"), including less than $11 \%$ of those under age twenty-five, received treatment. ${ }^{75}$ Moreover, despite the still growing opioid epidemic, the percentage of individuals with OUD receiving substance abuse treatment has remained relatively stagnant. ${ }^{76}$

These low treatment participation numbers, as well as the personal and financial costs associated with untreated opioid addiction, reflect the lack of evidence-based responses to the opioid epidemic. Those suffering from OUD often face the harsh reality that even when they wish to address their addiction, the help and treatment needed is too often unavailable. Their friends and family members are forced to sit idly by and witness the effects of OUD on their loved ones because, despite their best efforts, they too cannot find the individual the help or treatment needed to address the individual's OUD. Perhaps the most cruel and tragic fact is that we know that effective evidence-based treatment exists but it is not accessible to those who need it most.

\section{B. Medication Assisted Treatment ("MAT")}

As described in Section I, opioid use is associated with severe adverse effects, including, in some cases, addiction and death. Somewhat counterintuitively, opioids can also be used to treat opioid misuse and addiction. ${ }^{77}$ Indeed, medication-assisted treatment ("MAT"), which combines counseling with medication therapy, is widely recognized as the most effective treatment for OUD. ${ }^{78}$

${ }^{72}$ Anil G. Suryaprasad et al., Emerging Epidemic of Hepatitis C Virus Infections Among Young Nonurban Persons Who Inject Drugs in the United States, 2006-2012, 59 CliniCAL InfECTIOUS DISEASES 1411 (2014).

73 Ind. State Dep't of Health, HiV Outbreak in Southeastern Indiana (2015), http://www.in.gov/ [https://perma.cc/Q8NN-HRM8].

${ }^{74}$ Rudd, et al., supra note 52, at 1380 (2015).

75 U.S. DeP'T OF Health AND Human Services, Behavioral Health Barometer: United STATES, (2015), http://www.samhsa.gov/ [https://perma.cc/AHJ4-8QY8].

${ }^{76}$ Brendan Saloner \& Shankar Karthikeyan, Changes in Substance Abuse Treatment Use Among Individuals with Opioid Use Disorders in the United States, 2004-2013, 314 [J]AMA 1515 (2015) ("During the decade from 2004 to 2013, use of treatment remained low for individuals with OUDs and did not increase after accounting for changing population characteristics, underscoring substantial room for improvement.") (Importantly, this study did not measure MAT use.) Id.

77 See, e.g., World Health Org., Guidelines for the Psychosocially Assisted Pharmacological Treatment of Opioid Dependence 7 (2009), http://apps.who.int [https://perma.cc/VTL4-7WQG].

78 See generally U.S. DeP’T Health \& Hum. Servs., Pub No. (SMA)12-4214, MedicationAssisted Treatment for Opioid Addiction in Opioid Treatment Programs (2012), 
The federal Food and Drug Administration ("FDA") has approved three medications for the treatment of OUD: methadone, buprenorphine, and naltrexone. ${ }^{79}$ However, effective MAT for OUD generally involves methadone or buprenorphine, and, as such, this article does not discuss naltrexone in-depth. ${ }^{80}$ Methadone, approved by the FDA in 1972 for treating opioid addiction, ${ }^{81}$ is a long-acting full mu opioid agonist with a half-life between twenty-four to thirty-six hours, thereby allowing for once-a-day treatment. ${ }^{82}$ The drug has a relatively safe profile when used for treating opioid addiction. ${ }^{83}$ Buprenorphine received FDA approval for use in treating opioid addiction in 2002. ${ }^{84}$ The drug can remain effective for up to seventy-two hours with proper dosing, and because it is only a partial mu opioid agonist, increased dosages generally only produce a

http://store.samhsa.gov/ [https://perma.cc/V69Q-8EJG]; see also WORLD HEALTH ORG., Substitution MAINTENANCE THERAPY IN THE MANAGEMENT OF OPIOID DEPENDENCE AND HIV/AIDS PREVENTION 13 (2004) ("Substitution maintenance therapy is one of the most effective types of pharmacological therapy of opioid dependence; see also Rolley E. Johnson et al., A Comparison of Levomethadyl Acetate, Buprenorphine, and Methadone for Opioid Dependence, 343 NEW ENG. J. MED.1290, 1290-97 (2000); see also ANDY GRAY, SySTEMATIC REVIEW OF THE SAFETy of Buprenorphine, Methadone, AND NAltreXone (2007), http://www.who.int/ [https://perma.cc/QN6G-JV5P] (Background document prepared for Technical Development Group for the WHO Guidelines for Psychosocially Assisted Pharmacotherapy of Opioid Dependence, Geneva).

79 Suzanne Gelber Rinaldo \& David W. Rinaldo, Advancing Access to Addiction MEdicAtions: ImplicATIONS FOR Opioid AdDiction TREATMENT 13-15 (2013), http://www.asam.org [https://perma.cc/87DK-5KRJ].

${ }^{80}$ Naltrexone is a pure opioid antagonist that blocks the effects of other opioids, but does not reduce cravings and has shown little efficacy in treating opioid addiction. See Hilary Smith Connery, Medication-Assisted Treatment of Opioid Use Disorder: Review of the Evidence and Future Directions, 23 Harvard Rev. Psychiatry 63, 64 (2015) (noting studies demonstrating naltrexone's poor efficacy in treating OUD).

${ }^{81}$ Inst. of Med., Federal Regulation of Methadone Treatment 1 (Richard A. Rettig \& Adam Yarmolinsky eds., 1995) (methadone was first approved in 1947 for use as an analgesic and antitussive), http://www.nap.edu/catalog/4899/federal-regulation-of-methadone-treatment [https://perma.cc/CE5W-W8PZ].

82 Medication-Assisted Treatment for Opioid AdDiction in Opioid Treatment Programs, supra note 78, at 18, 42.

${ }^{83}$ See James R. Roberts, Deaths During Methadone Maintenance, 31 EMERGENCY MED. News, May 2009, at 10 ("[Methadone Maintenance Therapy] does not impair cognitive function, has no adverse effects on mental capability or intelligence, and doesn't keep you from working. Once a steady state is obtained, methadone is not overly sedating or intoxicating, and it doesn't keep you from driving a car."); James R. Roberts, Methadone Maintenance: The Basics, 31 EMERGENCY MED. NEWS, Feb. 2009, at 9, 10 ("Although methadone is a potent narcotic, more deaths are reported from methadone prescribed for pain than methadone obtained from maintenance programs ... The safety of MMT is well established. The drug has no long-term harmful effects to the heart, kidney, lungs, and liver.").

${ }^{84}$ James R. Roberts, Buprenorphine: A Drug You Need to Know About, 30 EMERGEnCY MeD. NEWS, Dec. 2008, at 7, 7-8. 
longer duration of action rather than greater agonist effects. ${ }^{85}$ This "ceiling effect" renders buprenorphine generally safer than methadone. ${ }^{86}$ Between 2009 and 2013, the number of opiatedependent individuals receiving methadone and buprenorphine increased by $17 \%$ and 100\%, respectively. ${ }^{87}$

Numerous studies have demonstrated MAT's efficacy. For example, one study found that individuals receiving MAT are 50\% less likely to relapse than those receiving non-medicationassisted therapy. ${ }^{88}$ Others note the significantly lower mortality rates associated with the availability and use of MAT. ${ }^{89}$ In a meta-analysis of studies on MAT in prison settings, researchers found increased participation in treatment post-release, as well as substantially reduced heroin use and syringe sharing. ${ }^{90}$ More generally, MAT is "associated with decreased injecti[on] drug use,

${ }^{85}$ Id.; Medication-Assisted Treatment for Opioid AdDiction In Opioid Treatment PROGRAMS, supra note 78, at 30.

86 MedicAtion-Assisted TREATMEnt FOR Opioid AdDiction IN Opioid Treatment PROGRAMS, supra note 78, at 30 ("As a result [of buprenorphine's ceiling effect], there is a greater margin of safety from death by respiratory depression when increased doses of buprenorphine are used, compared with increased doses of full opioid agonists. Buprenorphine overdose is uncommon, although it has been reported in France, and it is associated almost always with injection of buprenorphine coupled with ingestion of high doses of benzodiazepines, alcohol, or other sedative-type substances (citation omitted).").

${ }^{87}$ Behavioral HeAlth Barometer: United States, 2015, supra note 75 at 18.

${ }^{88}$ Sean M. Murphy et Al., Show Me the Money: Economic Evaluations of Opioid Use DiSORDER INTERVENTIONS 4 (2016), http://ldi.upenn.edu [https://perma.cc/G79N-VJX5] (“A study of Medicaid patients found that those receiving either BMT or MMT were 50\% less likely to relapse than those receiving behavioral treatments only.").

${ }^{89}$ Methadone Maintenance: The Basics, supra note 83, at 10 ("The one-year mortality rate for a patient in MMT is about one percent compared with eight percent among those who use alternative methods or stay with heroin."); Nora D. Volkow et al., Medication-Assisted Therapies - Tackling the Opioid-Overdose Epidemic, 370 NEW ENG. J. MED. 2063, 2064 (2014); citing Robert P. Schwartz et al., Opioid Agonist Treatments and Heroin Overdose Deaths in Baltimore, Maryland, 1995-2009, 103 AM. J. PuB. HeAlth 917 (2013). ("A study of heroin-overdose deaths in Baltimore between 1995 and 2009 found an association between the increasing availability of methadone and buprenorphine and an approximately $50 \%$ decrease in the number of fatal overdoses."), http://www.nejm.org [https://perma.cc/D8RQ-K2UD]; John R.M. Caplehorn et al., Methadone Maintenance and Addicts' Risk of Fatal Heroin Overdose, 31 SUBSTANCE UsE \& MISUSE 177, 185-86 (1996) (methadone reduces the risk of death among opioid dependent individuals by $400 \%)$.

90 Dagmar Hedrich et al., The Effectiveness of Opioid Maintenance Treatment in Prison Settings: A Systematic Review, 107 ADDICTION 501, $501 \quad$ (2012), http://onlinelibrary.wiley.com/doi/10.1111/j.1360-0443.2011.03676.x/epdf [https://perma.cc/HW2S-B74A]. 
decreased criminal activity, increased retention in treatment for chemical dependence, increased adherence to HIV medication, improved family relations, and successful return to employment." 91

Despite its proven efficacy, MAT has been implemented in less than $50 \%$ of private sector addiction treatment programs and only $34.4 \%$ of opiate-dependent individuals in such programs receive MAT. $^{92}$ Numerous factors contribute to this low utilization of MAT, including misconceptions, stigma, and the lack of available prescribers. ${ }^{93}$ The legal regime controlling access to methadone and buprenorphine for opioid addiction treatment presents another significant barrier to increasing the use of MAT. The following sections describe this legal access regime, including their history and proposed changes.

\section{Federal Legal Regulation of MAT: Historical Context}

At the turn of the twentieth century, medical professionals commonly provided opioids and other drugs without legal restrictions, including for the treatment of addiction. ${ }^{94}$ Between 1912 and 1920, federal, state, and local agencies promoted maintenance clinics for drug-dependent individuals. ${ }^{95}$ However, in 1914, Congress passed the Harrison Narcotics Tax Act, which imposed licensing, tax, prescription, and record requirements on physicians providing opiate and cocoa products, as well as restricted physicians from dispensing and distributing such products except "in the course of his professional practice." 96 Importantly, federal officials interpreted the law as prohibiting physicians from prescribing opiate and cocoa products to drug-dependent individuals. ${ }^{97}$ As a result, enforcement of the Harrison Narcotics Act effectively ended addiction maintenance treatment for nearly a half-century. ${ }^{98}$

91 Open SOC'y InST., BARRIERS TO ACCESS: MEDICATION-ASSISTED TREATMENT AND INJECTION-DRIVEN HIV EPIDEMICS 1 (2009), https://www.opensocietyfoundations.org [https://perma.cc/YF94-88AP] (internal citation omitted).

92 Hannah K. Knudsen et al., Adoption and Implementation of Medications in Addiction Treatment Programs, 5 J. OF ADDICT MED. 21, 21 (2011), https://www.ncbi.nlm.nih.gov/ [https://perma.cc/LS73-ASC3].

${ }^{93}$ Volkow et al., supra note 89, at 2064-065.

94 Ellen M. Weber, Failure of Physicians to Prescribe Pharmacotherapies for Addiction: Regulatory Restrictions and Physician Resistance, 13 J. HeAlth CARE L. \& POL'Y 49, 56 (2010). ${ }^{95} \mathrm{Id}$.

${ }^{96}$ Harrison Narcotics Act of 1914, Pub. L. No. 63-223, 38 Stat. 785.

${ }^{97}$ Weber, supra note 94 at 57-58 (noting that while this provision was initially rejected by the Supreme Court, subsequent amendments to the law and other Supreme Court cases upheld the prohibition on "physicians [ ] from prescribing heroin and cocaine to patients with addictions.").

${ }^{98} \mathrm{Id}$. at 60 ("All maintenance clinics were shuttered by 1925."); INSTITUTE OF MEDICINE(U.S.), Federal Regulation of Methadone Treatment, 93 (eds; Richard Rettig \& Adam Yarmonlinski) (1995) (noting the closure of clinics using morphine to treat opiate addiction and the Federal Bureau of Narcotics' 40 year "antimaintenance position."). The American Medical Association also opposed opioid maintenance therapy. See Jerome Jaffe \& Charles O'Keefe, From Morphine Clinics to Buprenorphine: Regulating Opioid Agonist Treatment of Addiction in the United States, 70 DRUG \& Alcohol DePENDENCE S3 (2003). 
In 1965, two doctors, Vincent Dole and Marie Nyswander, published a landmark study in the Journal of the American Medical Association highlighting the effectiveness of methadone to treat heroin addiction. ${ }^{99}$ This and similar research lead to the rapid increase in using methadone to treat opioid addiction under Investigational New Drug ("IND") applications ${ }^{100}$ issued by the FDA, ${ }^{101}$ and the number of methadone maintenance patients rose from less than 400 in 1968 to 73,000 in $1973 .^{102}$

At the same time, the legal landscape for opioid addiction treatment was also evolving. In 1970, responding to concerns over methadone diversion and addiction, the FDA proposed a new rule establishing protocols for methadone treatment under INDs; the rule was finalized in April 1971. ${ }^{103}$ In October 1970, Congress passed the Comprehensive Drug Abuse Prevention and Control Act ("CDAPCA") addressing "research, treatment, and prevention of drug abuse and drug dependence, and with drug abuse law enforcement authority." 104 In April 1972, the FDA proposed new regulations on methadone treatment. ${ }^{105}$ These regulations, finalized in December 1972,

99 Victor Dole \& Marie Nyswander, A Medical Treatment for Diacetylmorphine (Heroin) Addiction A Clinical Trial with Methadone Hydrochloride, 193 [J]AMA 646 (1965).

100 See M. E. Blair Holbein, Understanding FDA Regulatory Requirements for Investigational New Drug Applications for Sponsor-Investigators, 57 J. InVESTIGATIVE MED. 689, 690-91 (2009), https://www.ucdmc.ucdavis.edu/ [https://perma.cc/8S94-ZUT7]. Generally, federal law requires an approved marketing application before a drug may be shipped across state lines. However, an exemption procedure known as an Investigational New Drug ("IND") application allows researchers to obtain FDA approval to ship a drug across state lines for experimental and investigational uses. In other words, "[t]he IND is the mechanism by which the [drug's] investigator or sponsor provides the requisite information [to the FDA about the safety of the intended research study] to obtain authorization to administer an investigational agent to human subjects (or an approved drug used for a new indication or a new population of patients."

101 Jaffe \& O'Keefe, supra note 98, at S4.

102 Federal Regulation of Methadone Treatment, supra note 98.

${ }^{103}$ Id. at 128; Jaffe \& O'Keefe, supra note 98 at S4-S5.

${ }^{104}$ Comprehensive Drug Abuse Prevention and Control Act of 1970, Pub. L. No. 91-513, 84 Stat. 1236 (1970); Federal Regulation Of Methadone Treatment, supra note 98 at 123. Title II of the CDAPCA, the Controlled Substances Act ("CSA"), established five schedules for controlled substances, 21 U.S.C. $\S 812$, and required registration with the federal Drug Enforcement Administration ("DEA") before manufacturing, distributing, or dispensing a controlled substance. 21 U.S.C. $\S 822$. The CDAPCA intended "to clarify for the medical profession ... the extent to which they may safely go in treating narcotic addicts as patients," and, in a shift in federal policy, declared that, "the health establishment, not the law enforcement community, would determine the scope of practice of medicine in [treating narcotic addiction.]" Federal Regulation of Methadone Treatment, supra note 98 at 123-124. The CDAPCA "charged the Secretary of Health, Education, and Welfare, to 'determine the appropriate methods of professional practice in the medical treatment of the narcotic addiction of various classes of narcotic addicts." Id. The Secretary of Health, Education, and Welfare is now known as the Secretary of Health and Human Services.

${ }^{105}$ Federal Regulation of Methadone Treatment, supra note 98 at 129. 
established the modern regulatory framework for methadone treatment. ${ }^{106}$ The regulations limited methadone dispensing to federally licensed programs and approved hospital pharmacies, restricted patient eligibility for participation, required physician justification for high dosages, and specified criteria for granting and rescinding take-home doses. ${ }^{107}$

Congress complemented these new FDA regulations with the passing of the Narcotic Addict Treatment Act of 1974 ("NATA"). ${ }^{108}$ NATA, which amended the CSA, required medical professionals treating opioid addiction with opioids to obtain a separate DEA registration, established the National Institute on Drug Abuse, and retained the Secretary of Health, Education, and Welfare's role in setting medical practice standards for addiction treatment. ${ }^{109}$ The law represented Congress' formal recognition of the practice of using opioids to treat opioid addiction and was the first time that federal statutes defined "detoxification" and "maintenance" treatment. 110 Minor revisions to the methadone treatment regulations in 1980 and 1989 represented the only changes to this federal legal landscape between 1974 and 2000. ${ }^{11}$

\section{Federal Regulation of Methadone}

At the federal level, the legal requirements for prescribing and dispensing methadone depend on its intended purpose. When used to treat pain, methadone is subject to the same requirements and restrictions applicable to all other Schedule II controlled substances, such as OxyContin. ${ }^{112}$ However, federal regulations specify more rigorous requirements and limitations for methadone detoxification and maintenance therapy ("methadone therapy") for treating opioid addiction. ${ }^{113}$

${ }^{106}$ Federal Regulation of Methadone Treatment, supra note 98 at 93-94, 129.

${ }^{107}$ Id at $129-134$.

${ }^{108}$ Narcotic Addict Treatment Act of 1974, Pub. L. No. 93-281, 88 Stat. 124 (1974).

109 Medication-Assisted Treatment fOr Opioid AdDiction IN Opioid Treatment Programs, supra note 78 at 21; Federal REgulation of METhadone TrEatMent, supra note 98 at 134-135; Jaffe \& O'Keefe, supra note 98, at S5.

110 MedicAtion-Assisted TREATMENT FOR Opioid AdDiction IN Opioid TREATMEnT PROGRAMS, supra note 78 at 21. (The 1972 FDA regulations represented the first time federal law defined detoxification and maintenance treatment); see also FEDERAL REGULATION OF METHADONE TREATMENT, supra note 98 at 129.

111 Federal Regulation of Methadone Treatment, supra note 98 at 136-148; Jaffe \& O'Keefe, supra note 98, at S6 (noting that the FDA revisions "were relatively minor, mostly having to do with urine testing, on-site services, and easing constraints on admissions.").

112 Prescriptions, DRUG ENFORCEMENT ADMIN., http://www.deadiversion.usdoj.gov [https://perma.cc/SDD9-HML8] ("Federal law and regulations do not restrict the prescribing, dispensing, or administering of any schedule II, III, IV, or V narcotic medication, including methadone, for the treatment of pain, if such treatment is deemed medically necessary by a registered practitioner acting in the usual course of professional practice.") (last visited October 13, 2016).

113 See 21 U.S.C. 823(g) (2008) (applying additional requirements to dispensing "narcotic drugs to individuals for maintenance treatment or detoxification treatment."); 21 C.F.R. 1306.07(a) (2005). Federal law defines two types of methadone therapy: detoxification and maintenance treatment. Detoxification therapy is defined as "the dispensing of an opioid agonist 
These include requirements on who can provide and receive methadone therapy, as well as where and how methadone therapy can be provided. ${ }^{114}$ States and local governments may also impose additional requirements on methadone therapy. ${ }^{115}$

treatment medication in decreasing doses to an individual to alleviate adverse physical or psychological effects incident to withdrawal from the continuous or sustained use of an opioid drug and as a method of bringing the individual to a drug-free state within such period" 42 C.F.R. $\S 8.2$ (2016). Detoxification treatment includes both short-term and long-term detoxification. Short-term detoxification treatment is defined as "detoxification treatment for a period not in excess of 30 days." Id. Long-term detoxification treatment is defined as "detoxification treatment for a period more than 30 days but not in excess of 180 days." Maintenance treatment is defined as "the dispensing of an opioid agonist treatment medication at stable dosage levels for a period in excess of 21 days in the treatment of an individual for opioid addiction." Id. Maintenance treatment includes both interim and comprehensive maintenance treatment. Interim maintenance treatment is defined as "maintenance treatment provided in conjunction with appropriate medical services while a patient is awaiting transfer to a program that provides comprehensive maintenance treatment." Id. Comprehensive maintenance treatment is defined as "maintenance treatment provided in conjunction with a comprehensive range of appropriate medical and rehabilitative services." Id.

${ }^{114}$ See 42 C.F.R. $\S 8$ (2015) These regulations underwent major revision in 2001. See Opioid Drugs in Maintenance and Detoxification Treatment of Opiate Addiction Final Rule, 66 Fed. Reg. 4076 (Jan. 17, 2001) (codified at 21 CFR § 291, 42 C.F.R. § 8). In 2003, buprenorphine was added to the list of approved opioid treatment medications that OTPs may use. Opioid Drugs in Maintenance and Detoxification Treatment of Opiate Addiction; Addition of Buprenorphine and Buprenorphine Combination to List of Approved Opioid Treatment Medications, 68 Fed. Reg. 27937 (May 22, 2003) (codified at 42 C.F.R. § 8).

11542 C.F.R. \& 8.11(f)(1) (2016) ("OTPs shall comply with all pertinent State laws and regulations. Nothing in this part is intended to limit the authority of State and, as appropriate, local governmental entities to regulate the use of opioid drugs in the treatment of opioid addiction."). The differing requirements imposed by state law are beyond the scope of this article. 
Subject to limited exception, ${ }^{116}$ federal law limits methadone therapy to accredited and certified opioid treatment programs ("OTP"). ${ }^{117}$ As a condition to this certification, OTPs must provide the methadone therapy in accordance with federal treatment standards, ${ }^{118}$ although the programs may apply for exemptions from these requirements. ${ }^{119}$ Moreover, practitioners providing methadone therapy must obtain a separate annual registration from the DEA. ${ }^{120}$

Federal law also requires individuals seeking methadone therapy to meet specified criteria based on their age and the type of treatment sought. ${ }^{121}$ For maintenance treatment, an individual must meet the DSM-IV criteria for addiction to an opioid drug and must have become "addicted at least 1 year before admission for treatment." 122 The one-year requirement may be waived for individuals recently released from incarceration, pregnant women, and previously treated patients. ${ }^{123}$ Persons under age eighteen must also "have two documented unsuccessful attempts at short-term detoxification or drug-free treatment within a 12-month period." 124 Although

116 There are two relevant exemptions to the requirement that methadone only be dispensed by OTPs when used for detoxification or maintenance treatment. First:

[A] physician who is not specifically registered to conduct a narcotic treatment program [may] administer[] (but not prescrib[e]) narcotic drugs to a person for the purpose of relieving acute withdrawal symptoms when necessary while arrangements are being made for referral for treatment. Not more than one day's medication may be administered to the person or for the person's use at one time. Such emergency treatment may be carried out for not more than three days and may not be renewed or extended.

21 C.F.R. $\S$ 1306.07(b) (2005). Second, “a physician or authorized hospital staff [may] administer or dispense narcotic drugs in a hospital to maintain or detoxify a person as an incidental adjunct to medical or surgical treatment of conditions other than addiction." Id. $\S 1306.07$ (c).

117 See 42 C.F.R. $\$ 8.11$ (a)(1) (2016) ("An OTP must be the subject of a current, valid certification from SAMHSA to be considered qualified by the Secretary under section 303(g)(1) of the Controlled Substances Act (21 U.S.C. 823(g)(1)) to dispense opioid drugs in the treatment of opioid use disorder"). Note that OTP refers to both the program and practitioner; see id. $\S 8.2$ (defining OTP as "a program or practitioner engaged in opioid treatment of individuals with an opioid agonist treatment medication") (emphasis added).

118 See 42 C.F.R. $\S 8.11(f)(7)$ (2016).

${ }^{119}$ See id. $\S 8.11$ (h) ("An example of a case in which an exemption might be granted would be for a private practitioner who wishes to treat a limited number of patients in a non-metropolitan area with few physicians and no rehabilitative services geographically accessible and requests exemption from some of the staffing and service standards").

${ }^{120}$ See 21 U.S.C. $\S 823(\mathrm{~g})(1)(2016)$.

${ }^{121}$ See 42 C.F.R. § 8.12(e) (2016).

${ }^{122}$ See id. $\S 8.12(\mathrm{e})(1)$.

${ }^{123}$ See id. $\S 8.12(\mathrm{e})(3)$ (2016) (This exception is limited to six months after release for patients released from penal institutions and two years after discharge for previously treated patients).

${ }^{124} I d . \S 8.12(\mathrm{e})(2)$. 
detoxification treatment is available for any person meeting the diagnostic criteria established by the OTP, individuals are limited to two detoxification treatment episodes per year. ${ }^{125}$

In addition to these provider and patient qualifications, federal regulations also specify the services OTPs must provide and how OTPs may dispense the methadone. At the most general level, OTPs must provide "adequate medical, counseling, vocational, educational, other assessment and treatment services." 226 This includes an initial full medical examination, ${ }^{127}$ as well as initial and periodic assessment services to create and revise treatment plans. ${ }^{128}$ Counseling must cover not only substance abuse ${ }^{129}$ but also prevention of exposure to and transmission of HIV, ${ }^{130}$ community resources, vocational rehabilitation, education, and employment services. ${ }^{131}$

The provision of the methadone itself is also strictly regulated. OTPs may only provide methadone in oral form. ${ }^{132}$ The initial dose must not exceed 30 milligrams, and the entire dose provided on the first day of treatment must not exceed 40 milligrams. ${ }^{133}$ By default, patients must take the methadone under supervision; ${ }^{134}$ however, patients in comprehensive maintenance treatment may receive unsupervised "take-home" dosages under limited circumstances, ${ }^{135}$ such as when the clinic is closed. ${ }^{136}$ If an OTP medical director determines based on specified factors that "a patient is responsible in handling opioid drugs for unsupervised use," 137 an individual may

${ }^{125} I d . \S 8.12(\mathrm{e})(4)$.

12642 C.F.R. $\S 8.12(\mathrm{f})(1)(2016)$.

${ }^{127}$ Id. $\S 8.12(\mathrm{f})(2)$.

${ }^{128}$ Id. $\S 8.12(\mathrm{f})(4)$.

${ }^{129}$ Id. $\$ 8.12(\mathrm{f})(5)(\mathrm{i})$.

${ }^{130} \mathrm{Id}$ § 8.12(f)(5)(ii).

13142 C.F.R. $\$ 8.12(\mathrm{f})(5)($ iii) (2016).

${ }^{132}$ Id. $\S 8.12(\mathrm{~h})(3)(\mathrm{i})$.

${ }^{133}$ Id. $\S 8.12(\mathrm{~h})(3)(\mathrm{ii})$. The total dose for the first day may exceed 40 milligrams if "the program physician documents in the patient's record that 40 milligrams did not suppress opiate abstinence symptoms."

134 Id. $\S 8.12(\mathrm{i})(4)$. Unsupervised or take-home doses are prohibited for short-term detoxification and interim maintenance treatment.

${ }^{135}$ Id. $\S 8.12(\mathrm{i})$.

13642 C.F.R. $\$ 8.12(\mathrm{i})(1)$ (2016). (“Any patient in comprehensive maintenance treatment may receive a single take-home dose for a day that the clinic is closed for business, including Sundays and State and Federal holidays").

${ }^{137}$ Id. $\$ 8.12(\mathrm{i})(2)$. These factors include the:

(i) [a]bsence of recent abuse of drugs (opioid or nonnarcotic), including alcohol; (ii) [r] egularity of clinic attendance; (iii) [a]bsence of serious behavioral problems at the clinic; (iv) [a]bsence of known recent criminal activity, e.g., drug dealing; (v) [s]tability of the patient's home environment and social relationships; (vi) [1] ength of time in comprehensive maintenance treatment; (vii) [a]ssurance that take-home medication can be safely stored within the patient's home; and (viii) [w] hether the rehabilitative benefit the patient derived from decreasing the frequency of clinic attendance outweighs the potential risks of diversion. 
receive a specified number of take-home doses based on how long the individual has been in treatment. ${ }^{138}$ This includes a single dose each week during the first ninety days of treatment, two doses per week in the second ninety days of treatment, three doses per week in the third ninety days of treatment, a six-day supply "in the remaining months of the first year," a two-week supply after one year of continuous treatment, and a one month supply after two years of continuous treatment. ${ }^{139}$

\section{E. Federal Regulation of Buprenorphine}

In 2002, the FDA approved buprenorphine for treating opioid dependence, ${ }^{140}$ and the DEA rescheduled the drug from a Schedule V to a Schedule III controlled substance. ${ }^{141}$ Two years earlier, in October 2000, Congress passed the Drug Addiction Treatment Act of 2000 ("DATA 2000"). ${ }^{142}$ The law amended the CSA to allow practitioners meeting certain qualifying criteria to prescribe and dispense Schedule III, IV, and V controlled substances approved by the FDA for addiction treatment outside OTPs and without receiving a separate DEA registration. ${ }^{143}$ These two events created the current regulatory scheme for buprenorphine-based MAT.

DATA 2000 requires physicians to obtain a waiver by submitting a notification to the Secretary of Health and Human Services of the physician's intent to prescribe and dispense buprenorphine (or other Schedule III-V controlled substances) for the treatment of opioid dependence. ${ }^{144}$ This waiver must contain a certification that the physician is qualified to prescribe the medications for treating opioid dependence, "has the capacity to refer [ ] [their] patients . . . for appropriate counseling and other appropriate ancillary services," 145 and will comply with limitations on the total number of patients the physician may treat at any one time. ${ }^{146}$ Physicians are considered qualified to dispense buprenorphine to treat opioid dependence if they are licensed under state law

13842 C.F.R. $\S 8.12(i)(3)(2016)$.

${ }^{139}$ Id. $\S 8.12(\mathrm{i})(3)(\mathrm{i})-(\mathrm{vi})$.

${ }^{140}$ Buprenorphine: A Drug You Need to Know About, supra note 84, at 7.

${ }^{141}$ Schedules of Controlled Substances: Rescheduling of Buprenorphine From Schedule V to Schedule III, 67 Fed. Reg. 62,354 (Oct. 7, 2002) (to be codified at 21 C.F.R. pt. 1308). The DEA specifically cited DATA 2000's allowing office-based MAT with buprenorphine as a factor in rescheduling the drug. See id. at 62,357 ("High-dose, sublingual tablets intended for narcotic treatment and utilized outside the constraints of traditional narcotic treatment programs increases the risk that these products will be diverted, trafficked and abused. Simply stated, providing an abusable substance to known drug abusers imparts enhanced risks"). However, the DEA denied rescheduling on this basis alone. Id. at 62,363 ("The proposed placement of buprenorphine in Schedule III was not made on the basis of making buprenorphine products available for officebased narcotic treatment . . . [a]s part of our scheduling review, DEA did consider the impact of buprenorphine treatment products used within the context of office-based practice") Id.

${ }^{142}$ Children's Health Act of 2000, Pub. L. No. 106-310, 114 Stat. 1101, § 3501-3502.

14321 U.S.C. $\$ 823(\mathrm{~g})(2)(2016)$.

${ }^{144}$ Id. $\S 823(\mathrm{~g})(2)(\mathrm{B})(2016) ; 21$ C.F.R. $\S 1301.28(\mathrm{a}),(\mathrm{b})(1)(2016)$.

14521 C.F.R. $\S 1301.28($ b)(1)(i)-(iii) (2016).

14621 U.S.C. $\S 823(\mathrm{~g})(2)(\mathrm{B})(\mathrm{i})-(\mathrm{iii})$ (2016); 21 C.F.R. $\S 1301.28(\mathrm{~b})(1)(\mathrm{i})$-(iii) (2016). 
and meets at least one specified educational or experience requirements. ${ }^{147}$ A physician may treat only up to thirty patients at any one time during the first year the physician treats opiate-dependent patients under a DATA 2000 waiver. ${ }^{148}$ In subsequent years and upon notifying the Secretary of Health and Human Services, a physician may treat up to 100 patients at any one time. ${ }^{149}$

On July 8, 2016, SAMHSA, a division of the Department of Health and Human Services, finalized revisions to the OTP regulations relating to buprenorphine-based MAT. ${ }^{150}$ Effective August 8, 2016, these new regulations increase the patient limit to 275 for qualified practitioners providing buprenorphine-based MAT. ${ }^{151}$ To qualify for these increased patient limits, the practitioner must both (1) possess a DATA 2000 waiver allowing them to treat up to 100 patients for at least one year and (2) possess a subspecialty board certification in addiction medicine or addiction psychiatry or practice in a "qualified practice setting." 152 These qualified practice settings must ensure patients can access emergency care when the practice is closed, provide access to case management services, use health information technology systems such as electronic health

14721 U.S.C. $\S 823(\mathrm{~g})(2)(\mathrm{G})(\mathrm{ii})$ (2016). These educational and experience requirements are:

(1) Holding a certification in addiction from the American Board of Medical Specialties, the American Society of Addiction Medicine, or the American Osteopathic Association;

(2) Completing at least 8 hours of training in "the treatment and management of opiatedependent patients" from "the American Society of Addiction Medicine, the American Academy of Addiction Psychiatry, the American Medical Association, the American Osteopathic Association, the American Psychiatric Association, or any other organization that the Secretary [of Health and Human Services] determines is appropriate for [these] purposes;"

(3) Participating "as an investigator in one or more clinical trials leading to the approval of a narcotic drug in schedule III, IV, or V for maintenance or detoxification treatment, as demonstrated by a statement submitted to the Secretary by the sponsor of such approved drug;"

(4) Having "such other training or experience as the State medical licensing board (of the State in which the physician will provide maintenance or detoxification treatment) considers to demonstrate the ability of the physician to treat and manage opiate-dependent patients;" or

(5) Having "such other training or experience as the Secretary considers to demonstrate the ability of the physician to treat and manage opiate-dependent patients," as specified by regulation.

14821 U.S.C. $\S 823(\mathrm{~g})(2)(\mathrm{B})(\mathrm{iii})$ (2016); 21 C.F.R. $\S 1301.28(\mathrm{~b})(1)(\mathrm{iii})$ (2016).

${ }^{149} \mathrm{Id}$.

${ }^{150}$ Medication Assisted Treatment for Opioid Use Disorders, 81 Fed. Reg. 44,712 (July 8, 2016) (to be codified at 42 C.F.R. pt. 8).

${ }^{151} \mathrm{Id}$. at 44,712, 44,738 (to be codified at 42 C.F.R. $\S 8.610$ ).

${ }^{152} \mathrm{Id}$. at 44,738 (The practitioner must also not have "had his or her enrollment and billing privileges in the Medicare program revoked under $\S 424.535$ of this title" and have "been found to have violated the Controlled Substances Act pursuant to 21 U.S.C. 824(a)"). 
records, utilize their state prescription drug monitoring program ("PDMP"), and accept third-party payment. ${ }^{153}$

Similarly, the Comprehensive Addiction and Recovery Act of 2016 ("CARA"), signed into law on July 22, 2016, makes additional changes to federal law aimed at increasing access to MAT. ${ }^{154}$ Most prominently, CARA amends the CSA to allow certain nurse practitioners and physician assistants to provide MAT with Schedule II, IV, or V controlled substances,${ }^{155}$ including buprenorphine. To qualify, the nurse practitioner or physician assistant must be "licensed under State law to prescribe schedule II, IV, or V medications for the treatment of pain" and have sufficient training. ${ }^{156}$ CARA also includes more specific content requirements for physician education when used by the physician to qualify for a DATA 2000 waiver. ${ }^{157}$

\section{F. Insurance Coverage of MAT}

Historically, many insurance plans, particularly those available to lower income people, provided poor or no coverage for OUD treatment. ${ }^{158}$ Moreover, health insurance providers legally

${ }^{153} I d$. (to be codified at 42 C.F.R. $§ 8.615$ ).

${ }^{154}$ Comprehensive Addiction and Recovery Act of 2016, Pub. L. No. 114-198, 130 Stat. 695.

${ }^{155}$ Id. $\S 303(\mathrm{a})(1)(\mathrm{C})(\mathrm{v})(\mathrm{iv})(\mathrm{I})$ (to be codified at 21 U.S.C. $\S \S 823(\mathrm{~g})(2)(\mathrm{G})(\mathrm{iv})(\mathrm{I})$ ). CARA includes a sunset provision providing that its authorization for nurse practitioners and physician assistants to provide MAT expires on October 1, 2021. Id. (to be codified at 21 U.S.C. $\S$ $823(\mathrm{~g})(2)(\mathrm{G})(\mathrm{iii})(\mathrm{II}))$.

${ }^{156}$ Id. $\S 303(\mathrm{a})(1)(\mathrm{C})(\mathrm{v})(\mathrm{iv})(\mathrm{II}-\mathrm{III})$ (to be codified at 21 U.S.C. $\S 823(\mathrm{~g})(2)(\mathrm{G})(\mathrm{iv})(\mathrm{II}-\mathrm{III})$ ). Nurse practitioners and physician assistants can meet the training requirement either by (1) completing at least twenty-four hours of initial training addressing the same topics required for physicians, see infra note 155, or (2) "ha[ving] such other training or experience as the Secretary determines will demonstrate the ability of the nurse practitioner or physician assistant to treat and manage opiate-dependent patients." Id. Nurse practitioners and physician assistants must be "supervised by, or work in collaboration with, a qualifying physician, if the nurse practitioner or physician assistant is required by State law to prescribe medications for the treatment of opioid use disorder in collaboration with or under the supervision of a physician." Id.

${ }^{157}$ Id. $\S 303(\mathrm{a})(1)(\mathrm{C})(\mathrm{iv})(\mathrm{IV})$ (to be codified at 21 U.S.C. $\left.\S 823(\mathrm{~g})(2)(\mathrm{G})(\mathrm{ii})(\mathrm{IV})\right)$. These topics are:

opioid maintenance and detoxification; appropriate clinical use of all drugs approved by the Food and Drug Administration for the treatment of opioid use disorder; initial and periodic patient assessments (including substance use monitoring); individualized treatment planning, overdose reversal, and relapse prevention; counseling and recovery support services; staffing roles and considerations; diversion control; and other best practices, as identified by the Secretary.

158 Mary Giliberti et Al., COVERAge for All: InClusion of Mental Illness AND Substance Use Disorders in State Health Care Reform Initiatives 7 (National Alliance on Mental Illness and National Council for Community Behavioral Healthcare, June 2008) (finding 
could, and generally did, impose more stringent requirements and limitations on coverage for mental health services, including treatment for OUD, than for other medical services. ${ }^{159}$ These requirements and limitations made it extraordinarily difficult and costly for individuals with OUDeven those with health insurance-to obtain needed care. Beginning in 1996, Congress took several steps to increase access to mental health care, but the impact on access to substance use disorder ("SUD") treatment, and more specifically MAT, remains unclear. ${ }^{160}$

In 1996, Congress enacted the Mental Health Parity Act ("MPHA"), prohibiting large group insurers from imposing more restrictive annual and lifetime financial limitations on mental health services than those applicable to other medical care. ${ }^{161}$ However, the law did not address SUD, did not require insurers to offer mental health coverage at all, and explicitly permitted cost sharing and utilization limitations. ${ }^{162}$ In 2008, the Paul Wellstone and Pete Domenici Mental Health Parity and Addiction Equity Act of 2008 ("MHPAEA") strengthened the MPHA by adding SUD benefits and prohibiting insurers from imposing more restrictive financial and treatment limitations on mental health and SUD benefits. ${ }^{163}$ Moreover, regulations promulgated under the MHPAEA required that health plans, that offered benefits for a specific substance use condition, in any one of six classifications (inpatient, in-network; inpatient, out-of-network; outpatient, in-network; outpatient, out-of-network; emergency care; and prescription drugs), also provide benefits for that condition in every other classification in which medical or surgical benefits were offered. ${ }^{164}$ However, the law's exemption for small employers ${ }^{165}$ left a large segment of the population without its protections.

The Patient Protection and Affordable Care Act ("ACA"), ${ }^{166}$ signed into law on March 23, 2010, requires all individual and small group health insurance policies to provide coverage for

that only $28 \%$ of surveyed states have at least one program for the uninsured that provides SUD services at parity).

159 See Ellen Weber, Equality Standards for Health Insurance Coverage: Will the Mental Health Parity and Addiction Equity Act End The Discrimination?, 43 Golden Gate U. L. REV. 179, 181 (April 2013).

${ }^{160}$ See Michael C. Barnes \& Stacey L. Worthy, Achieving Real Parity: Increasing Access to Treatment for Substance Use Disorders Under the Patient Protection and Affordable Care Act and the Mental Health and Addiction Equity Act, 36 U. ARK. LiTTLE RocK L. REV. 555, 565-73 (2014). States have also taken action to increase mental health and substance use disorder treatment parity. Id. at 573-76.

${ }^{161}$ Departments of Veterans Affairs and Housing and Urban Development, and Independent Agencies Appropriations Act of 1997, Pub. L. No. 104-204, 110 Stat. 2874, 2944 (1996).

$162 \mathrm{Id}$.

${ }^{163}$ Emergency Economic Stabilization Act of 2008, Pub. L. No. 110-343, 122 Stat. 3765, 3881. Financial requirements included "deductibles, copayments, coinsurance, and out-of-pocket expenses," and treatment limitations included "limits on the frequency of treatment, number of visits, days of coverage, or other similar limits on the scope or duration of treatment." Id.

16445 C.F.R. $\S 146.136(\mathrm{c})(2)(\mathrm{ii})(\mathrm{A})(2015)$.

${ }^{165}$ Id. $\S 146.136(\mathrm{c})(4)(\mathrm{iii})$ (see Example 11, Exemptions).

166 Patient Protection and Affordable Care Act, Pub. L. No. 111-148, 124 Stat. 119 (2010), amended by Health Care and Education Reconciliation Act of 2010, Pub. L. No. 111-152, 124 Stat. 1029 [hereinafter ACA]. 
SUD as an essential health benefit ("EHB")-the first such requirement in federal law. ${ }^{167}$ It also extended the MHPAEA's requirements to all insurance plans offered through an ACA Marketplace, ${ }^{168}$ all benchmark and benchmark-equivalent Medicaid plans, ${ }^{169}$ and Medicaid plans operated by managed care organizations. ${ }^{170}$ Moreover, the ACA prohibits insurers from refusing to cover people currently experiencing $\mathrm{SUD}^{171}$ or with a history of SUD, ${ }^{172}$ as well as prohibits insurers from charging individuals with SUD higher premiums or cost sharing based on their condition. ${ }^{173}$

Although these changes are welcome and will likely continue to increase access to SUD treatment, including MAT for OUD, they are not a panacea. One study examining the MHPAEA found that the law did not increase the number of individuals receiving SUD treatment and found "no significant change in identification, treatment initiation or treatment engagement." 174 Another recent study revealed that approximately half of individuals with unmet mental health treatment needs, including substance use disorder, reported cost and insurance coverage as a barrier to access. ${ }^{175}$ Noncompliance with federal requirements likely contributes to these results. A June 2016 report from the National Center on Addiction and Substance Abuse revealed that the vast majority of ACA benchmark plans do not satisfy the ACA and MHPAEA's requirements. ${ }^{176}$ More

16742 U.S.C. $\S \S 18021(\mathrm{a})(1)(B), 18022$ (2015); 45 C.F.R. $\S 156.110(\mathrm{a})(5)$ (2015).

16842 U.S.C. $§ 18031(\mathrm{j})$ (2015) (applying the MHPAEA's parity requirements to qualified health plans).

${ }^{169}$ Id. § 1396u-7(b)(6)(A) (applying the MHPAEA's parity requirements to benchmark and benchmark-equivalent Medicaid plans).

${ }^{170}$ Id. $\S 1396 \mathrm{u}-2(\mathrm{~b})(8)$ (2015) (applying the MHPAEA's parity requirements to Medicaid managed care organizations).

${ }^{171}$ Id. § 300gg-3(a) (2015)

${ }^{172}$ Id. § 300gg-4(a) (2015).

${ }^{173}$ Id. §300gg-4(b)(1).

${ }^{174}$ Susan H. Busch et. al., The Effects of Federal Parity on Substance Use Disorder Treatment, 20 AM. J. MANAGED CARE 76, 76 (2014).

175 Timothy B. Creedon \& Benjamin Lê Cook, Access To Mental Health Care Increased But Not For Substance Use, While Disparities Remain, 35 Health AfF. 1017, 1019 (2016).

176 Nat'l Ctr. on AdDiction \& Substance Abuse, Uncovering Coverage Gaps: A REVIEW OF AdDICTION BENEFITS IN ACA Plans 1 (June 7, 2016), http://www.centeronaddiction.org [https://perma.cc/TMS3-QYKL]. The report found that:

Over two-thirds of the plans do not comply with the ACA's requirements for coverage of SUD benefits. II. Eighteen percent of the plans violate parity requirements; 31 percent of the plans contain possible parity violations. III. None of the plans provide comprehensive coverage for SUDs by covering the full array of critical benefits without harmful treatment limitations; the most frequently excluded or not explicitly covered benefits are residential treatment and methadone maintenance therapy. IV. Plan documents for 88 percent of the 2017 EHB-benchmark plans lack sufficient detail to fully evaluate compliance with the ACA and/or the adequacy of SUD benefits. 
aggressive enforcement may be necessary to ensure the ACA fulfills its promise of expanding access to SUD.

\section{NALOXONE ACCESS}

\section{A. Access to Emergency Overdose Treatment}

As described in Section I, opioids can be useful in the treatment of some types of pain, providing relief and improving productivity for many people. However, because the same receptors that mediate pain also affect a number of other systems and functions, opioid therapy can result numerous psychological and physiological side effects. ${ }^{177}$ For example, approximately $25 \%$ of patients prescribed opioids suffer from nausea, while between $40 \%$ and $95 \%$ of opioid patients report chronic opioid-induced constipation ("OIC"). ${ }^{178}$

More worrying from a public health standpoint are the sedating and depressant qualities of opioids. ${ }^{179}$ OPRs, either alone or in combination with other medications, can reduce the body's sensitivity to oxygen and carbon dioxide levels. ${ }^{180}$ This causes the respiratory system to work less efficiently, resulting in a reduction in the amount of oxygen available to the brain and other organs. ${ }^{181}$ Early reversal of this opioid-induced respiratory depression ("OIRD") is critical, as the risk of irreversible cell death increases the longer this condition, termed hypoxia, persists. ${ }^{182}$ Over 28,600 Americans died in 2014 of opioid-related overdose, and an unknown, but much larger number, likely suffered minor to major hypoxia-related disability. ${ }^{183}$

177 Benyamin et al., supra note 48, at S106-09 (listing multiple effects of opioid therapy in addition to analgesia).

178 John. M. Swegle \& Craig Logemann, Management of Common Opioid-Induced Adverse Effects, 74 AM. FAM. PHYSICIAN 1347, 1348-49 (2006) (describing that because of the prevalence of opioid prescribing and related OIC, several drugmakers now market medications specifically to treat the condition). A telling example of the widespread nature of the problem was manifsted in the 2016 Super Bowl, which saw approximately $\$ 10$ million spent on ads to raise awareness of OIC). Ed Silverman, Drug makers stand firm on TV ad for opioid-induced constipation, STAT (Feb. 17, 2016), https://www.statnews.com [https://perma.cc/UZT6-LE96].

179 Nathan Cherny et al., Strategies to Manage the Adverse Effects of Oral Morphine: An Evidence-Based Report, 19 J. CliniCAL OnCOLOGY 2542, 2547 (2001) (reporting that 20\% to 60\% of patients receiving oral morphine for chronic cancer pain experience sedation or drowsiness).

${ }^{180}$ Jason M. White \& Rodney J. Irvine, Mechanisms of Fatal Opioid Overdose, 94 ADDICTION 961 (1999) (providing an exhaustive explanation of the manner in which opioids cause OIRD and resulting fatal overdose).

181 See K. T. S. Pattinson, Opioids and the Control of Respiration, 100 BRITISH J. OF ANAESTHESIA 747, 750 (2008).

182 Carine Michiels, Physiological and Pathological Responses to Hypoxia, 164 AM. J. PATHOLOGY 1875 (2004).

183 The exact number is reported to be 28,647 , but since approximately $20 \%$ of overdose deaths do not list the drug(s) involved, this number is an undercount. Rose A. Rudd et al., Increases in Drug and Opioid Overdose Deaths-United States, 2000-2014, 64 MORBIDITY AND MorTALILTY WKLY. REP. 1378, 1380 (2016). 
Luckily, a medication exists that effectively and reliably reverses OIRD. This medication, called naloxone, is a pure opioid antagonist that binds to opioid receptors but does not activate them. ${ }^{184}$ Since naloxone has a higher affinity for these receptors than all opioids in common use, it displaces those opioids, restoring normal respiratory response. ${ }^{185}$ First approved by the FDA in 1971, naloxone is a prescription medication but not a controlled substance. ${ }^{186}$ It is on the WHO's List of Essential Medicines and is the standard treatment for opioid overdose. ${ }^{187}$ Although naloxone is carried by most paramedics in the United States, it has not historically been prescribed for outpatient use, likely due in part to the fact that it was originally approved only for injection. ${ }^{188}$

With the increase in opioid overdose deaths, there has been movement to decrease the amount of time overdose patients are in OIRD by increasing access to naloxone among laypeople, including people who use drugs and their friends and family members. As early as the mid-1990's, naloxone was being dispensed to people who use drugs ("PWUD") in several countries in Europe. ${ }^{189}$ Programs to distribute naloxone to PWUD in the United States began operating shortly thereafter. ${ }^{190}$ By 2010, nearly 200 community naloxone distribution programs were operating in the United States and participants in those programs had received more than 50,000 kits, which were used to reverse more than 10,000 overdoses. ${ }^{191}$ By July 2014, the number of naloxone

${ }^{184}$ See James M. Chamberlain \& Bruce L. Klein, A Comprehensive Review of Naloxone for the Emergency Physician, 12 AM. J. EMERGENCY MED. 650 (1994) (for an exhaustive explanation of the mechanism and effect of naloxone).

185 Id.

186 Daniel P. Wermeling, Review of Naloxone Safety for Opioid Overdose: Practical Considerations for New Technology and Expanded Public Access, 6 THERAPEUTIC ADVANCES IN Drug SAFETY 20, 21 (2015) (Naloxone approved in 1971); see also Drug Enforcement Administration, Controlled Substances-Alphabetical Order (2016), http://www.deadiversion.usdoj.gov [https://perma.cc/BS4S-YZ4Z] (Naloxone not on list of controlled substances).

187 World Health Org., WHO Model List of Essential Medicines 4 (April 2015), http://www.who.int/ [https://perma.cc/QBM7-JT3R].

${ }^{188}$ Mark A. Merlin et al., Assessment of the Safety and Ease of Use of the Naloxone Autoinjector for the Reversal of Opioid Overdose, 7 OPEN ACCESS EMERGENCY MED. 21, 21-22 (2015); see also Corey S. Davis et al., Emergency Medical Services Naloxone Access: A National Systematic Legal Review, 21 ACAD. EMERGENCY MED. 1173, 1174-75 (2014) [hereinafter Emergengy Medical Services Naloxone Access].

${ }^{189}$ Bruno Simini, Bologna-Naloxone Supplied to Italian Heroin Addicts, 352 LANCET 967, 967 (1998) (case report describing the provision of naloxone to people who use heroin in the EmiliaRomagna region of Italy); Kerstin Dettmer et al., Take Home Naloxone and the Prevention of Deaths from Opiate Overdose: Two Pilot Schemes, 322 BMJ 895, 895-96 (2001) (describing a naloxone dispensing project in Jersey beginning in 1998 and in Berlin starting in 1999).

190 Phillip O. Coffin et al., Preliminary Evidence of Health Care Provider Support for Naloxone Prescription as Overdose Fatality Prevention Strategy in New York City, 80 J. OF URBAN HeALth 288 (2003) (noting that naloxone programs were operating in Chicago in 1999 and San Francisco and New Mexico by 2001).

${ }^{191}$ Eliza Wheeler et al., Community-Based Opioid Overdose Prevention Programs Providing Naloxone-United States, 2010, 61 Morbidity AND MorTALILTY WKLY. REP. 101 (Feb. 17, 2012) 
distribution sites had increased to 644 , and more than 150,000 people had received kits, with more than 26,000 potentially fatal overdose reversals reported. ${ }^{192}$ About $20 \%$ of the naloxone distributed through these programs was in a form suitable for use intranasally through an improvised nasal applicator. ${ }^{193}$ There has also been increasing interest in co-prescribing naloxone to patients being treated with opioids and to increase naloxone access through pharmacies. ${ }^{194}$ Recently released guidelines from the Centers for Disease Control and Prevention ("CDC"), for example, recommend that naloxone be co-prescribed for patients with a history of overdose, a history of a substance use disorder, higher opioid doses, or concurrent benzodiazepine use. ${ }^{195}$

Because time is of the essence in responding to an overdose, providing naloxone to people who are present or very close to the scene of an overdose may help reduce opioid overdose-related morbidity and mortality. Initial evidence of such efforts is positive. Massachusetts has been one of the most proactive states in providing naloxone to laypeople and distributing the medication through venues such as syringe access programs, addiction treatments programs, and community meetings. ${ }^{196}$ An extensive evaluation of this distribution scheme found that overdose rates were significantly lower in communities that had ready access to naloxone distribution sites compared to those that did not. ${ }^{197}$ A separate study of naloxone prescription in San Francisco found that longterm opioid patients who were prescribed naloxone had $47 \%$ fewer opioid-related emergency room visits in the six months following the prescription than similar patients who had not received naloxone. $^{198}$

(reporting that naloxone had been distrubted to a minimum of 53,032 people since 1996, with 10,171 reversals reported).

192 Eliza Wheeler, et al., Opioid Overdose Prevention Programs Providing Naloxone to Laypersons-United States, 2014, 64 Morbidity AND Mortalilty WKLy. ReP. 631 (June 19, 2015) (152,283 laypeople received naloxone and 26,463 reversals reported).

${ }^{193}$ Id.

194 Jamie K. Lim et al., Prescribe to Prevent: Overdose Prevention and Naloxone Rescue Kits for Prescribers and Pharmacists, 10 J. of AdDiction MED. 300, 302-05 (2016); Traci C. Green et al., Orienting Patients to Greater Opioid Safety: Models of Community Pharmacy-Based Naloxone, 12 HARM Reduction J. 1, 3 (2015); see also Corey Davis \& Derek Carr, State Legal Innovations to Encourage Naloxone Dispensing, J. AM. PHARMACISTS Ass'N (2017) (forthcoming).

195 Deborah Dowell et al., CDC Guideline for Prescribing Opioids for Chronic Pain--United States, 2016, 315 JAMA 1624, 1639 (2016).

196 Alexander Y. Walley et al., Opioid Overdose Rates and Implementation of Overdose Education and Nasal Naloxone Distribution in Massachusetts: Interrupted Time Series Analysis, 346 BMJ 1, 2 (2013).

${ }^{197}$ Id. at 4 (2013). See also Sarz Maxwell et al., Prescribing Naloxone to Actively Injecting Heroin Users: A Program to Reduce Heroin Overdose Deaths, 25 J. OF ADDICTIVE DisEASES 89, 89-93 (2008) (finding that a decrease was also observed after the initiation of a large-scale naloxone dispensing program in Chicago in 2001, but its reduction is observational).

198 Phillip O. Coffin et al., Nonrandomized Intervention Study of Naloxone Coprescription for Primary Care Patients Receiving Long-Term Opioid Therapy for Pain, ANNALS OF INTERNAL MED. 245, 249 (2016). 
The increased distribution of naloxone is also likely to save money in terms of reduced health care costs, as well as reductions in overdose-related disability and lost productivity. The most robust analysis to date found the distribution of naloxone to heroin users to be cost-effective, even using extremely conservative assumptions. ${ }^{199}$ A separate study noted that the cost of treating people who had overdosed in Rhode Island hospitals alone could have paid for more than 61,000 naloxone kits at the then-current cost of $\$ 15 .^{200}$ There is no evidence that the provision of naloxone increases risk-taking behavior. ${ }^{201}$

\section{B. Addressing Legal and Policy Barriers to Naloxone Access}

While naloxone distribution programs have expanded dramatically in the past decade, many of the early programs operated without clear legal authorization. Because naloxone is a prescription medication, it can be dispensed only on the order of a medical professional authorized to issue prescriptions. ${ }^{202}$ Unfortunately, many such professionals may be unaware of the practice of prescribing naloxone to their patients or may be wary of prescribing naloxone to patients who may be at risk of overdose due to concerns that doing so might increase their liability risk. ${ }^{203}$ Further reducing access, state medical practice laws typically prohibit physicians and other authorized prescribers from ordering medications for persons other than the person to whom they are to be administered (a process referred to as third-party prescription) or to a person the physician has not personally examined (a process referred to as prescription via standing order). ${ }^{204}$

${ }^{199}$ Philip O. Coffin \& Sean D. Sullivan, Cost-Effectiveness of Distributing Naloxone to Heroin Users for Lay Overdose Reversal, 158 ANNALS OF INTERNAL MED. 1, 6 (2013) (finding that "[n]aloxone distribution to heroin users would be expected to reduce mortality and be costeffective even under markedly conservative assumptions of use, effectiveness, and cost").

${ }^{200}$ Michael A. Yokell et al., Opioid Overdose Prevention and Naloxone Distribution in Rhode Island, 94 MED. HEALTH R.I. 240, 242 (2011).

${ }^{201}$ Maya Doe-Simkins et al., Overdose Rescues by Trained and Untrained Participants and Change in Opioid Use Among Substance-Using Participants in Overdose Education and Naloxone Distribution Programs: A Retrospective Cohort Study, 14 BioMedCentral PuB. Health 1, 8 (2014) (finding that "..training active substance users in overdose management and distributing nalxoone rescue kits does not lead opioid sers to increase their overall opioid use").

202 See 21 U.S.C. 353(b)(1)(B) (providing that under federal law, prescription medications "shall be dispensed only . . . upon a written prescription of a practitioner licensed by law to administer such drug. . . ."). In practice, this requirement has been interpreted to mean that such medications can be dispensed only on the prescription of a practitioner licensed to prescribe the drug.

${ }^{203}$ Leo Beletsky et al., Physicians' Knowledge of and Willingness to Prescribe Naloxone to Reverse Accidental Opiate Overdose: Challenges and Opportunities, 84 J. URB. HEALTH 126, 130 (2007) (finding that only about 23\% of physicians surveyed said that they "had heard of the practice of prescribing naloxone" to injection drug using patients, and a majority said that they would never consider prescribing naloxone to an injection drug using patient).

${ }^{204}$ Corey S. Davis \& Derek Carr, Legal Changes to Increase Access to Naloxone for Opioid Overdose Reversal in the United States, 157 Drug \& Alcohol DePENDENCE 112, 113 (2015) (desribing legal and policy barriers to naloxone access, as well as modifications to state law 
By June 2016, all but three states (Kansas, Montana, and Wyoming) had passed some form of legislation designed to improve layperson naloxone access. ${ }^{205}$ These laws have three main characteristics: 1) providing immunity to naloxone prescribers, dispensers, and administrators; 2) permitting naloxone to be prescribed to people who are not patients of the prescriber and dispensed by people not otherwise authorized to dispense prescription medications; and 3) providing limited criminal immunity to individuals who summon emergency responders in the event of an overdose. We will briefly go through these measures in turn.

\section{Immunity for Naloxone Prescribing, Dispensing, and Administration}

In general, the risk associated with prescribing or dispensing naloxone is no higher than other commonly undertaken medical activities and, may in fact, be lower than many. ${ }^{206}$ In fact, a recent review found not a single instance in which prescription, dispensing, or administration of naloxone, in the outpatient setting, had been the grounds for a lawsuit. ${ }^{207}$ Nevertheless, physicians tend to overestimate their risk of being sued for malpractice and related torts and may be wary of participating in naloxone programs or co-prescribing naloxone because of liability fears. ${ }^{208}$

To address these concerns and encourage the prescription, dispensing, and appropriate administration of naloxone, the majority of states have enacted laws that provide limited immunity to prescribers, dispensers, and administrators. Specifically, as of June 2016, thirty-seven states provide civil immunity to medical professionals who prescribe and dispense naloxone, thirty-three provide criminal immunity, and thirty-two provide protection from disciplinary action for actions

intended to address them); Corey S. Davis et al., Changing Law from Barrier to Facilitator of Opioid Overdose Prevention, 41 J. LAW, MED., \& ETHICs 33, 33-35 (2013) (describing state of law regarding naloxone access).

${ }^{205}$ Prescription DRUG AbUSE Policy System, http://pdaps.org/ [https://perma.cc/N9QY9KVG] (last visited Jan. 21, 2017) (click on "Expanded Access to Naloxone").

${ }^{206}$ Scott Burris et al., Legal Aspects of Providing Naloxone to Heroin Users in the United States, 12 INT'L J. OF DRUG POL'y 237, 246 (2001) (examining legal risks and concluding that prescribers can prescribe naloxone "without exposing themselves to a significant risk of increased liability for violation of federal or state law, or for malpractice"); Scott Burris et al., Stopping an Invisible Epidemic: Legal Issues in the Provision of Naloxone to Prevent Opioid Overdose, 1 DREXEL L. REV. 273, 314-18 (2009) [hereinafter Stopping an Invisible Epidemic] (describing the reasons that it would be difficult to win a tort suit against a prescriber who prescribes naloxone in their normal course of practice).

${ }^{207}$ This review was limited to cases in the Westlaw database. See also Corey S. Davis et al., Engaging Law Enforcement in Overdose Reversal Initiatives: Authorization and Liability for Naloxone Administration, 105 Am. J. Pub. HeAlth e1, e2 (2015).

${ }^{208}$ Ann G. Lawthers et al., Physicians' Perceptions of the Risk of Being Sued, 17 J. OF Health Pol., POL'Y \& L. 463, 468 (1992) ("Physicians do over-estimate the risk of being sued"); Emily R. Carrier et al., Physicians' Fears of Malpractice Lawsuits are Not Assuaged by Tort Reforms, 29 HeALth AFF. 1585, 1587 (2010) ("Concern about malpractice liability is pervasive among physicians"). 
related to naloxone prescribing and dispensing. ${ }^{209}$ Additionally, forty-two states provide civil immunity to lay administrators, and thirty-three provide criminal immunity to those individuals. ${ }^{210}$

\section{Prescribing Outside of the Traditional Prescriber Relationship}

While the FDA has the exclusive authority to approve prescription medications, the authority to determine which individuals are permitted to prescribe, the format prescriptions must take, who can dispense under a valid prescription, and nearly all other elements of prescribing and dispensing legend medications, is left to the states. ${ }^{211}$ States have some uniformity in these requirements. Prescriptions may generally only be issued by a person authorized to prescribe medications who is acting in good faith, in the usual course of professional practice, and for a legitimate medical purpose. The prescription of naloxone to a patient at risk of overdose, of course, fulfills all three criteria. ${ }^{212}$ However, in many cases, the person at risk may not present to the medical professional and admit to being at risk of overdose; rather, a parent, spouse, or concerned friend may approach the prescriber and ask for a prescription for naloxone for the person at risk. ${ }^{213}$ Under traditional rules of medical practice, the prescriber would not be permitted to issue a prescription to that person for use on a person with whom the prescriber does not have a clinician-patient relationship. ${ }^{214}$

To address this lack of access, states have adopted two separate but related provisions: those that permit naloxone to be prescribed to third parties, and those that permit naloxone to be prescribed via standing or protocol orders. Third party prescribing laws waive the general requirement that the prescriber and the person for whom the medication is intended (the patient at risk of overdose) establish the traditional professional-patient relationship, permitting naloxone to be prescribed to a patient for use on other individuals, such as the patient's friends, family members, and acquaintances. ${ }^{215}$ As of June 2016, forty-two states permit third party prescription of naloxone. ${ }^{216}$

Standing medication orders, in which a physician or other prescriber authorizes the provision of medication to a person who meets predetermined criteria, are common in medical practice. ${ }^{217}$

209 See Corey Davis et. Al, Legal Interventions to Reduce Overdose Mortality: Naloxone Access and Overdose Good SAmaritan Laws 7 (see Table 1) (The Network for Pub. Health L., 2012) [hereinafter LEGAL INTERVENTIONS TO REDUCE OVERDOSE MORTALITY].

${ }^{210} \mathrm{Id}$.

211 Stopping an Invisible Epidemic, supra note 206, at 290 ("Surprisingly, few states have explicit rules defining a physician's authority to prescribe or setting criteria for allowable prescriptions"). This is not true for controlled substances, which require, among other things, a license from the DEA to prescribe. As noted above, naloxone is not a controlled substance at the federal level or in any state.

${ }^{212}$ See id. at 297 ("In all states, a physician may prescribe naloxone to patients who are at risk of opiate overdose in any setting and certainly as part of an overdose prevention intervention").

${ }^{213}$ Davis \& Carr, supra note 204, at 114.

${ }^{214}$ Id.

${ }^{215}$ Id.

216 PRESCRIPTION DRUG ABUSE POLICY SYSTEM, http://pdaps.org/ [https://perma.cc/N9QY-9KVG] (last visited Jan. 21, 2017).

${ }^{217}$ Id. 
Perhaps the most widespread use of these orders is in the emergency medical system ("EMS"), whereby an agency medical director or similarly situated individual creates medication protocols to be followed by EMS personnel. ${ }^{218}$ Standing orders have also become widespread in the area of vaccination, where they are used to permit pharmacists or other providers to administer vaccinations for some common diseases without the recipient receiving an individual prescription for the vaccine. ${ }^{219}$ The majority of states have now extended this concept to the dispensing of naloxone, permitting the medication to be dispensed to any person who meets criteria specified by the prescriber. ${ }^{220}$ While these standing medication orders can be filled at pharmacies like any other prescription, as of June 2016, fourteen states also explicitly permit laypersons to dispense the medication pursuant to the order as well. ${ }^{221}$

\section{Overdose Good Samaritan Laws}

Among Christians, perhaps one of the most enduring Biblical stories is that of the Good Samaritan. ${ }^{222}$ The parable is prompted by a question from "a certain lawyer," who has inquired of Jesus how one might obtain eternal life. ${ }^{223}$ Jesus responded with the story of the "Good Samaritan": A traveler, presumably a Jew, is robbed, beaten, and left "half dead" on the side of the road. ${ }^{224}$ First a priest and then a Levite, despite seeing the man's distress, pass by on the other side of the road, failing to provide aid. ${ }^{225}$ However, a third man, a Samaritan, tended to the man's wounds, carried him to an inn, and paid the innkeeper to care for the man. ${ }^{226}$ The answer to the lawyer's question is then revealed: "Go, and do thou likewise." 227

Presumably in the spirit of that admonition, the majority of states have passed laws that have come to be known as "overdose Good Samaritan" laws. ${ }^{228}$ These laws are intended to at least

${ }^{218}$ See Emergengy Medical Services Naloxone Access, supra note 188, at 174.

219 Chyongchiou Jeng Lin et al., Cost-Effectiveness of Pneumococcal and Influenza Vaccination Standing Order Programs, 19 AM. J. MANAGING CARE e30, e30-31 (2013); see also Barbara H. Bardenheier et al., Are Standing Order Programs Associated With Influenza Vaccination?-NNHS, 2004, 11 J. AM. Med. Directors Ass'N 654, 654-61 (2010) (finding that standing order programs are association with influenza vaccination).

${ }^{220}$ PrescriPtion Drug AbUSE POlicy SYSTEM, http://pdaps.org/ [https://perma.cc/N9QY9KVG] (last visited Jan. 21, 2017).

${ }^{221} \mathrm{Id}$.

${ }^{222}$ Or, at least the term "Good Samaritan" has entered the general parlance; since many individuals who use the term seem unaware of its origin, the authors thought it important to summarize the parable here.

${ }^{223}$ Luke 10:25. The Gospel According to Luke, in which the parable appears, was, according to church tradition, penned by Luke the Evangelist, who is identified elsewhere in the Bible as a physician. Colossians 4:14 ("Luke, the beloved physician, and Demas, greet you").

${ }^{224}$ Luke 10:30.

${ }^{225} \mathrm{Id}$. at 10:31-32.

${ }^{226}$ Id. at $10: 33$.

${ }^{227}$ Id at 10:37.

${ }^{228}$ These laws are distinct from civil Good Samaritan laws, which provide civil immunity to responders who gratuitously offer medical care in emergencies. For a good overview of those laws, see Victoria Sutton, Is There a Doctor (and a Lawyer) in the House? Why our Good Samaritan 
partially address the uncomfortable fact that, despite recent statements to the effect that we "can't arrest our way out of' the problem of opioid-induced overdose, arrest is in fact the primary federal and state response to drug possession, sale, and related activities. ${ }^{229}$

To encourage people who witness an overdose, many of whom may be engaging in illegal activities, to summon first responders, the majority of states have now modified state criminal law to provide limited (in some cases very limited) immunity to individuals who summon emergency aid in the event of an overdose. ${ }^{230}$ The first such law was passed by New Mexico in $2007 .{ }^{231}$ As of June 2016, thirty-five other states and the District of Columbia have followed suit. ${ }^{232}$ As with naloxone access laws, these measures vary significantly between states. Most states provide a person who summons emergency responders in good faith protection from prosecution for minor drug possession, and eighteen also protect the caller from being arrested for those crimes. ${ }^{233}$ Twenty-three states provide protection from prosecution for paraphernalia possession, with thirteen providing protection from arrest for that crime. ${ }^{234}$

The general trend has been toward providing more robust protection. For example, as of June 2016, seventeen state laws provide that information obtained because a person called for assistance in an overdose cannot be used to violate that person's probation or parole. ${ }^{235}$ Uniquely, Vermont's overdose Good Samaritan law provides protection from citation, arrest, and prosecution from all controlled substance violations. $^{236}$

\section{Over the Counter Access to Naloxone}

Laws are Doing More Harm Than Good for a National Public Health Security Strategy: A FiftyState Survey, 6 J. of HeALTH \& BiomedicAL L. 261 (2010).

${ }^{229}$ See, e.g., Mark Tenia, 'We can't arrest our way out of it': Chesterfield Police Explore New Ways to Combat Heroin Epidemic, WRIC.COM (Mar. 16, 2016, 6:11 PM) (statement of Major Chris Hensley, Chesterfield County, VA Police) (“[W] can't arrest our way out . . . ." of the overdose problem), http://wric.com/ [https://perma.cc/9RGG-RCQH]; see also Fred Upton, Upton: We Can't Arrest Our Way Out of Opioid Epidemic, The Detroit News (Dec. 7, 2015, 11:34 PM) (statement of U.S. Rep. Fred Upton (R-MI)) ("We cannot arrest our way out of this epidemic"), http://www.detroitnews.com [https://perma.cc/KDX5-L5W8].

230 The Policy Surveillance Program, A LawAtlas ProJect, http://lawatlas.org/ [https://perma.cc/6P6U-H9JU] (last visited Jan. 21, 2017).
${ }^{231} I d$.
${ }^{232} I d$.
${ }^{233} I d$.
${ }^{234} I d$.
${ }^{235}$ Id.

${ }^{236}$ VT. STAT. ANN. tit. 18, § 4254(c) (2013) (“A person who is experiencing a drug overdose and, in good faith, seeks medical attention for himself or herself or is the subject of a good faith request for medical assistance shall not be cited, arrested, or prosecuted for a violation of this chapter ...."). "This chapter" is Chapter 84 of Title 18 and contains most of the state's laws related to licit and illicit drugs. 
State law changes to permit third party prescribing, standing orders, and lay dispensing attempt to address the main barrier to naloxone access: its status as a prescription medication. ${ }^{237}$ If the medication was instead available over-the-counter ("OTC"), most of these changes would be unnecessary. Regulatory authorities in several other countries have recently taken this or related steps. In February 2016, Australia rescheduled naloxone, making it available without a prescription, although it can still be purchased only from a pharmacist. ${ }^{238}$ Canada removed naloxone from the national Prescription Drug List in March 2016, permitting provinces and territories to make it available OTC. ${ }^{239}$ The United Kingdom has also moved to increase access to naloxone. While it remains a prescription medication, the prescription requirement has been waived in certain circumstances, such that it can be supplied by drug treatment service providers to any person who might be in a position to use it in an emergency. ${ }^{240}$ Unfortunately, the United States has not joined these countries, due in part to a much more onerous process for moving a prescription drug to OTC status and the lack of an intermediate classification.

The Federal Food, Drug, and Cosmetic Act of 1938 ["FDCA"] laid out the foundation for the control of therapeutic drugs in the United States. ${ }^{241}$ Although that Act codified a distinction between prescription and non-prescription drugs by exempting drugs dispensed by a prescription from some labeling requirements, it did not otherwise clearly delineate differences between the two classes. ${ }^{242}$ Although the FDA later issued regulations firming the lines between prescription

${ }^{237}$ In fact, these initiatives are often referred to as permitting naloxone to be dispensed "without a prescription." That statement is not correct. See Corey Davis, "Over the Counter" Naloxone Access, Explained, Network FOR PuB. HeAlth L. (Mar. 1, 2016, 10:40 AM), https://www.networkforphl.org [https://perma.cc/BW56-DF23].

238 See Simon R. Lenton et al., Australia Reschedules Naloxone for Opioid Overdose, 204 MED. J. OF AUSTL. 146, 146-47 (2016). Unlike many other countries, the United States does not have a formal class of "behind the counter" ("BTC") medications that can be obtained only from a pharmacist but that also do not require a prescription. See U.S. GOV'T ACCOUNTABILITY OfF., NonPrescription Drugs: CONSIDERATIONS REgarding a BEHIND-THE-COUNTER DRUg Class (United States Government Accountability Office, 2009), http://www.gao.gov/ [https://perma.cc/PX9G-CEK3]. However, a handful of medications are effectively BTC. For example, the Combat Methamphetamine Act of 2005, which was enacted as Title VII of the USA PATRIOT Improvement and Reauthorization Act of 2005, banned the OTC sale of pseudoephedrine, phenylpropanolamine, and ephedrine, but did not change their prescription status. Medications containing these drugs, therefore, are effectively BTC.

239 The Availability of Take-Home Naloxone in Canada, CCENDU Bulletin (Can. Ctr. on Substance Abuse, Ottawa, Ont.), Mar. 2016, at 1, 7.

240 See Pub. Health Eng., Guidance: Widening the Availability of Naloxone, Gov.UK , https://www.gov.uk [https://perma.cc/Q84B-NWGE] (last updated June 24, 2016); Pub. Health Eng., Take-Home Naloxone for Opioid Overdose in People Who Use Drugs, Gov.UK (Feb. 2015), http://www.nta.nhs.uk/ [https://perma.cc/8VZC-KJDB].

${ }^{241}$ Federal Food, Drug, and Cosmetic Act, 21 U.S.C. $§ 301$ (2016). The Act regulates a wide variety of related issues, from food additives to medical devices to bottled water.

${ }^{242}$ This exemption is now codified at 21 U.S.C. $§ 353(b)(2)$ (2016) (exempting drugs dispensed via prescription from certain requirements: 
and nonprescription drugs, it was not until 1951 that legislation, commonly referred to as the Durham-Humphrey Amendment, set out the requirements that must be met for medications to be approved for dispensing without a prescription order. ${ }^{243}$ The other major piece of legislation in this area, the 1962 Kefauver-Harris Amendment, added to the existing body of law by requiring that drugs be both safe and effective, and set out the basis for the New Drug Application ("NDA") system still in use today. ${ }^{244}$

Prior to the Durham-Humphrey Amendment, drug makers, rather than a regulatory body, generally determined whether medications would be marketed as prescription-only or OTC. ${ }^{245}$ Subsequent to the Amendment, all new medications designed to be used by humans and all requests to change the prescription status of an existing medication are required to be submitted to the FDA for approval. ${ }^{246}$ If the FDA determines that the medication is not safe to use except 1) "under the supervision of a practitioner licensed by law to administer" the drug, or 2) is limited because of its approved applications to be used only under the professional supervision of such a practitioner, it must be made available only under a prescription. ${ }^{247}$ Drugs that were originally approved for prescription use can be moved OTC if the FDA Commissioner determines that the prescription requirement is:

not necessary for the protection of the public health by reason of the drug's toxicity or other potentiality for harmful effect, or the method of its use, or the collateral measures necessary to its use, and he finds that the drug is safe and effective for use in self-medication as directed in proposed labeling. ${ }^{248}$

if the drug bears a label containing the name and address of the dispenser, the serial number and date of the prescription or of its filling, the name of the prescriber, and, if stated in the prescription, the name of the patient, and the directions for use and cautionary statements, if any, contained in such prescription).

${ }^{243}$ Humphrey-Durham Amendments of 1951, Pub. L. No. 82-215, 65 Stat. 648 (codified as amended at Federal Food, Drug, and Cosmetics Act Amendments (1951)), https://www.gpo.gov [https://perma.cc/DA62-DG5Z]. Hubert Humphrey, Jr., Senator from South Dakota, and Carl Durham, Representative from North Carolina, were both current or former pharmacists. Originally codified at 21 U.S.C. $\S 503$, the Act, as amended, is now found at 21 U.S.C. $\S 353$ (b). The history of the OTC/prescription classification is, of course, much richer than the very brief summary provided here. For an excellent review of the Durham-Humphrey Amendment and related issues, see Gregory W. Reilly, THE FDA AND PLAN B: The Legislative History of the DurhamHumphrey Amendments and the Consideration of Social Harms in the Rx-OTC Switch, HARV. L. SCH. (May 12, 2006), https://dash.harvard.edu [https://perma.cc/Z93L-USUA].

${ }^{244}$ Drug Amendments of 1962, Pub. L. No. 87-781, 76 Stat. 780 (codified as amended at 21 U.S.C. $\S 301$ et seq. (1962)).

245 Richard R. AbOOD, Pharmacy Practice AND THE LAW 119 (6th ed. 2011).

24621 U.S.C. $\S 355$ (2016).

24721 U.S.C. $\$ 353(\mathrm{~b})(1)(\mathrm{A})-(\mathrm{B})(2013)$.

24821 C.F.R. § 310.200(b) (2016). 
There are three regulatory pathways available for switching a prescription medication to OTC: a manufacturer may file a NDA, a manufacturer or other party can petition the FDA for rescheduling, or the FDA can reclassify an active ingredient through publishing what is referred to as OTC monograph. ${ }^{249}$ The NDA and petition processes are used to reclassify a specific product, while the monograph covers the active ingredient itself. ${ }^{250}$ Monographs have been entered in twenty-six broad therapeutic categories, such as antacids, sleep aids, and antiperspirants. ${ }^{251}$ While a monograph switch would make all naloxone formulations OTC, an NDA can be used to move only some naloxone formulations OTC while keeping others prescription-only. ${ }^{252}$ Such a situation may be appropriate with naloxone, where the formulations designed for layperson administration may be appropriate for OTC marketing, while older, injectable formulations may not be. ${ }^{253}$

In general, a medication must meet four main criteria to be approved for OTC dispensing: 1) the drug must treat a condition that the patient can identify without the benefit of a medical professional; 2) the patient must be able to understand how to use the medication by reading the

${ }^{249}$ The particular NDA used is referred to in different sources as a Supplemental New Drug Application or an Abbreviated New Drug Application. ABOOD, supra note 245, at 122; see also Regulatory Mechanisms for Marketing OTC Drug Products, FDA, http://www.fda.gov [https://perma.cc/XLB6-UE6R] (last updated Feb. 10, 2016); see also Small Business Assistance: Frequently Asked Questions on the Regulatory Process of Over-the-Counter (OTC) Drugs, FDA, http://www.fda.gov/ [https://perma.cc/9DZ6-HQ4V] (last updated Jan. 7, 2015). The specific process for the "Prescription to OTC switch" is long, complicated, and beyond the scope of this article.

${ }^{250}$ Leah Christl, Introduction to Nonprescription Products, FDA 13, http://www.fda.gov [https://perma.cc/4Q5U-EVDC] (last visited Oct. 26, 2016). Monographs establish conditions under which an OTC ingredient is Generally Recognized as Safe and Effective ("GRASE"). Id. at 21.

${ }^{251}$ Karen Murry Mahoney, Overview of the Over-The-Counter Drug Monograph Process, FDA 21 (June, 10, 2016), http://www.fda.gov/ [http://perma.cc/7VHT-SXJM] .

252 See Drug Approvals: Circumstances Under Which an Active Ingredient May Be Simultaneously Marketed in Both a Prescription Drug Product and an Over-the-Counter Drug Product, 70 Fed. Reg. 52,050-01, 52,051 (Sept. 1, 2005) ("FDA has interpreted the language in 503(b)(1) of the act to allow marketing of the same active ingredient in products that are both prescription and OTC, assuming some meaningful difference exists between the two that makes the prescription product safe only under the supervision of a licensed practitioner"). Examples of this move include ibuprofen that becomes Rx above 400mg; Clortimazol (Rx for candidiasis, and OTC for athlete's foot, ringworm, and jock itch); or Meclizine (Rx for vertigo, and OTC for nausea with motion sickness). Id.

${ }^{253}$ See Kathryn Foxhall, OTC naloxone? It's Possible, DrugTopics.Com (May 15, 2012), http://drugtopics.modernmedicine.com/ [https://perma.cc/5FVU-UZ2R] ("Classifying [naloxone] OTC would probably be accomplished through the new drug application (NDA) process, [Andrea Leonard-Segal, MD, director, FDA Division of Nonprescription Clinical Evaluation, Office of Nonprescription Products] said"). In general, injectable medications are not appropriate for OTC labeling, although some types of insulin are available over the counter. See Sarah Jane Tribble, You Can Buy Insulin Without a Prescription, But Should You? KAISER HeAlth News (KHN) (Dec. 14, 2015), http://khn.org [http://perma.cc/H9GM-9V7E]. 
package label; 3) the drug must be effective when used as recommended; and 4) the drug must be safe when used as indicated and have a low potential for misuse and abuse. ${ }^{254}$

In practice, a switch for either of the naloxone formulations currently approved for layperson use would hinge largely on a showing that the patient can self-diagnose, self-treat, and self-manage using the medication. ${ }^{255}$ Reclassification of those devices would likely rest heavily on data showing that the consumer can safely and effectively use the device without interaction with a medical professional, as well as read and understand the label. ${ }^{256}$ According to the FDA, other questions that would need to be addressed include "what the impact would be if the injectable were no longer a prescription drug; how to deal with management of withdrawal reactions; whether naloxone's availability would encourage drug abuse or discourage people from calling 911 after an incident; and what education and advertising might look like." ${ }^{257}$ In a 2016 blog post, the FDA's Commissioner of Food and Drugs said that the agency "is reviewing options, including over-thecounter availability, to make naloxone more accessible. That work builds on FDA's recent approval of intranasal naloxone." ${ }^{258}$ However, it is not clear what formal steps, if any, have been taken to move some or all naloxone formulations OTC.

\section{CONCLUSION}

In 2011, the Office of National Drug Control Policy set the goal of decreasing unintentional opioid overdose deaths by $15 \%$ within five years. ${ }^{259}$ It was not to be. Fatal overdoses of heroin and

${ }^{254}$ See generally Eric. P. Brass, Changing the Status of Drugs from Prescription to Over-theCounter Availability, 345 NEw ENG. J. OF MED. 810, 811-813 (2001); see Christl, supra note 250 at 6; see also Regulation of Nonprescription Products, FDA, http://www.fda.gov [https://perma.cc/4J3X-YP4M] (last updated Feb. 24, 2015) ("OTC drugs generally have these characteristics: their benefits outweigh their risks; the potential for misuse and abuse is low; consumer can use them for self-diagnosed conditions; they can be adequately labeled; health practitioners are not needed for the safe and effective use of the product").

255 See Foxhall, supra note 253 (statement of Andrea Leonard-Segal, MD, director, FDA Division of Nonprescription Clinical Evaluation, Office of Nonprescription Products) ("For naloxone, data will be needed to assess whether the individual administering the drug could properly diagnose the opioid overdose and determine that it is appropriate to give naloxone based upon the information in the drug facts label").

256 Over the Counter Human Drugs; Labeling Requirements, 64 Fed. Reg. 13,254, 13,254 (Mar. 17, 1999). The information that must be contained on the OTC product label is set out in federal regulations and includes elements such as the active ingredient of the medication, the purpose of the medication, the indications, and any warnings. See 21 C.F.R $\S 201.60$ (2016); id. at $\S 61$; id. at $\S 66(\mathrm{c})$; id. at $\S 211.132$ (tamper-evident packaging requirements).

${ }^{257}$ Foxhall, supra note 253.

258 R. Califf, Changing course: A new approach to opioid pain medication at FDA (2016), http://blogs.fda.gov/ [https://perma.cc/QV2X-MQMC].

${ }^{259}$ Executive Office of the President, Epidemic: Responding to America's Prescription Drug Abuse Crisis, Office of National Drug Control Policy (2011), https://www.whitehouse.gov [https://perma.cc/NY5P-N56C]. 
OPRs increased by approximately 10,000 per year from 2010 to $2014,{ }^{260}$ which saw the highest number of fatal overdoses on record. ${ }^{261}$ While a number of policy approaches have been attempted to address this unprecedented increase in potentially preventable overdose deaths, it is not clear that any, alone or in combination, have had or will have a significant effect. ${ }^{262}$ What began primarily as a prescription drug epidemic has been shifting towards heroin, with corresponding increases in fatalities. ${ }^{263}$ A recent wave of deaths associated with illicit fentanyl analogs may signal the latest-and most deadly-wave of the epidemic. ${ }^{264}$

Most epidemics follow a similar curve-with deaths rising before eventually falling again-and it is likely that this one will as well. ${ }^{265}$ The question, from a standpoint of morality and public health, is how to shift that curve so that the fall is quicker and steeper than it would be if left to follow its natural course. While the devil is often in the details, we think there are several broad types of interventions that would likely shift that curve if brought to scale.

First, it is necessary to bring the number of inappropriate opioid prescriptions as close to zero as possible. Some interventions, such as those that target "pill mills," are steps in this direction. ${ }^{266}$ However, most problematic prescriptions do not come from prescribers acting illegally, but rather from medical professionals who are unaware that they are prescribing inappropriately. The type and amount of pain and addiction training in medical education should be dramatically increased,

${ }^{260}$ National Institute on Drug Abuse, Overdose Death Rates (2015), https://www.drugabuse.gov/ [https://perma.cc/NQ65-2V2P] (19,687 in 2010 to 29,467 in 2014).

${ }^{261}$ R. A. Rudd, et al., Increases in Drug and Opioid Overdose Deaths-United States, 20002014, 64 MORBIDITY AND MORTALITY WKLY. REP. 1378, 1380 (2016) ("More persons died from drug overdoses in the United States in 2014 than during any previous year on record.").

${ }^{262}$ It's actually quite depressing. T. M. Haegerich, et al., What we know, and don't know, about the impact of state policy and systems-level interventions on prescription drug overdose, 145C DRUG AlcoHol DEPEND 134 (2014) (Evidence of improved health outcomes [from state legal and ppolicy efforts] is weak.); E. Meara, et al., State Legal Restrictions and Prescription-Opioid Use among Disabled Adults, 375 N ENGL J MED 44 (2016) (among disabled Medicare beneficiaries, authors found "no significant associations between opioid outcomes and specific types of laws or the number of types enacted").

${ }^{263}$ While the absolute number of people using heroin in the United States is relatively low, heroin abuse is much more dangerous than prescription drug abuse. H. Hedegaard, et al., Drugpoisoning Deaths Involving Heroin: United States, 2000-2013, NCHS DATA BRIEF (2015) (heroin deaths nearly quadrupled from 2010 to 2013).

${ }^{264}$ See generally Rose A. Rudd, et al., Increases in Drug and Opioid Overdose Deaths-United States, 2000-2014, 64(50) MORBIDITY AND MORTALITY WKLY. REP. 1378-382 (2016).

265 Salima Darakjy, et al., Applying Farr's Law to Project the Drug Overdose Mortality Epidemic in the United States, 1 INJ. EPID.1, (2014), https://www.ncbi.nlm.nih.gov [https://perma.cc/2QYY-6N2P].

266 Tatyana Lyapustina, ET AL., Effect of a "Pill Mill" Law on Opioid Prescribing and Utilization: The Case of Texas, 159 DRUG Alcohol DePEND 190-197 (2016) (clinically significant reductions in opioid dose, volume, prescriptions and pills dispensed associated with introduction of pill mill law). 
and updated to reflect best evidence. ${ }^{267}$ We further suggest that insurer mechanisms be modified to incentivize evidence-based care and non-opioid therapy, such as the removal of methadone for pain from state Medicaid preferred drug lists, ${ }^{268}$ and that state regulatory boards be much more aggressive in investigating and, where warranted, suspending or terminating prescribers who are practicing below medical standards.

Second, as noted in this paper, MAT is the most effective current treatment for people with substance use disorder. Access to MAT should be dramatically increased, and governments and payors should re-examine policies and treatment modalities that do not include MAT for individuals with opioid use disorder. ${ }^{269}$ Access to naloxone should also be a priority, including addressing barriers raised by the cost of the medication. ${ }^{270}$ The slow shift from viewing opioid use disorder as a crime instead of the medical condition it is should be accelerated.

Finally, and perhaps most importantly, we must find better ways of treating pain. Research into additional non-opioid measures to relieve pain is desperately needed, and funding in this area should be dramatically and immediately increased. Humans have used opioids for their euphoric effects for thousands of years, and are likely to continue to do so. Everything possible, of course, should be done to ensure that humane, evidence-based treatment is available for those who want and need it. But the current epidemic is largely driven by well-intentioned attempts to treat pain with opioids. While they sometimes fulfill that goal, the side effects often outweigh the benefits. The millions of Americans-and the tens of millions of people worldwide-who suffer from pain with no good way to treat it deserve better.

267 See generally Corey S. Davis \& Derek Carr, Physician Continuing Education to Reduce Opioid Misuse, Abuse, and Overdose: Many Opportunities, few Requirements, 163 DRUG ALCOHOL DEPEND 100 (2016) (outlining state of opioid-related education requirements).

268 Christopher M. Jones, ET AL., Trends in Methadone Distribution for Pain Treatment, Methadone Diversion, and Overdose Deaths-United States, 2002-2014, 65(26) MORBIDITY AND MORTALITY WKLY. REP. 667, 669 (2016) (decrease in methadone overdose deaths associated with at least 16 states removing methadone from their preferred drug lists).

269 See generally Leo Beletsky, et al., Fatal Re-Entry: Legal and Programmatic Opportunities to Curb Opioid Overdose Among Individuals Newly Released from Incarceration, 7 NE. U. L.J. $155(2015)$.

270 Harrison Jacobs, The Price of the 'Antidote' to the Overdose Crisis is Skyrocketing, BUSINESS INSIDER (Aug. 1, 2016, 6:30 PM), http://www.businessinsider.com [https://perma.cc/MC29-59SS]. 